\title{
UNCERTAINTY OF RISK AND INCREASING RISK OF UNCERTAINTY IN BUSINESS DECISIONS
}

Iván Bélyácz - Katalin Daubner ${ }^{1}$

\begin{abstract}
Our paper follows the development of theory regarding the position of risk and uncertainty in economics from the publication of works by Knight (1921) and Keynes (1921) until the recent past. The starting point is presented by the relevant remarks of the thinkers of classical economics. Next, we describe the turning point related to Knight and Keynes and reveal the theoretical roots of risk taking. In the core chapter of the paper the authors make an attempt to re-interpret "animal spirits" as the intention for risk taking. A separate chapter is devoted to the relationship of rational choice and risk, and another one about the canonisation of risk in economics. In further parts of the paper, we examine the intentions to relativize the difference between risk and uncertainty, the negligence of uncertainty in the neo-classical system, the attempts to merge risk and uncertainty and the disruption of the unity of risk taking and risk bearing. Finally, the authors come to the conclusion that Knight's and Keynes' doctrines of risk and uncertainty have stood the test of time.
\end{abstract}

JEL codes: B26, D81, E12, Goo, G11

Keywords: risk, uncertainty, risk taking, risk bearing, animal spirits, rational choice

\section{INTRODUCTION}

Risk, Uncertainty and Profit by Knight and Treatise on Probability by Keynes on risk and uncertainty and the concept of probability were published one hundred years ago.

Their thoughts continue to be live and inspiring today. This paper is a tribute to the epoch-making work of the two great thinkers.

$1 \quad$ Iván Bélyácz, Academician, professor. E-mail: belyacz@ktk.pte.hu Katalin Daubner, Candidate of Science, associate professor. E-mail: daubnerkati@gmail.com. 
Risk is a concept appearing in several disciplines ${ }^{2}$, but all technical discussions can be represented by three components: first, one or several potential hazards; second, the probability of those hazards going active (often called exposure); and third, the probable counter-effect experienced when the hazard occurs. Risk is normally compared by the size of the relevant loss (Kimmons, 2003). The economic system prior to World War I was described as risk free. Lasting peace (in the appropriate time) within the economic system provided perfect conditions for decision making. During and after WW I, the assessment of probability and the aspects of risk in an economic system changed, and new concepts of understanding risk appeared in the form of uncertainty and rational decision making.

A big break in the assessment of risk occurred when the world war crushed the conventional wisdom of the previous era. The world which at one time seemed to be orderly and predictable turned out to be non-predictable and disorderly in extreme cases, as Bernstein wrote (1995:10). It is no surprise that Knight (1921) introduced the central topic of his great work as follows,

“...It is only in very special and crucial cases that anything like a mathematical (exhaustive and quantitative) study can be made."

It is no surprise either that Keynes' (1921) work on probability was, in fact, an attack on the idea that mathematics was able to define the future with any certainty. Mehr-Hedges (1962) have drawn up important principles related to corporate risk management decisions. According to the first one, decision makers should not risk more than the loss they can afford. According to the second one, decision makers should not take a risk for little. According to the third one, decision makers should consider the odds. With respect to the first principle, decision makers should be able to estimate potential loss arising from the exposure to risk, by the second one, they must measure the resources available to offset that potential risk and by the third one, decision makers must be able to develop tools to measure the costs and benefits of alternative cases of risk taking in given risk situations.

The basic difference between risk and uncertainty is based on how much a series of the outcomes of potential decisions and the probability of their occurrence is quantifiable. Uncertainty often refers to the fact that decision making is not easy to be quantified. Knight (1921) states uncertainty may be related both to decision outcomes and the probability of their occurrence, Uncertainty may also be relat-

2 The concepts of risk and uncertainty are both used in decision making and in everyday life. In the latter, however, the common use of the terms is significantly different from their professionalscientific definitions. The Oxford English Dictionary describes risk as "the possibility of something bad happening at some time in the future; a situation that could be dangerous or have bad results" and uncertainty as "the state of not knowing or of not being known exactly, the state of being uncertain". 
ed to decision makers' preferences (March, 1978). Quantifiability is the key feature of risk, but the relationship between the definition and measurement of risk is not linear. In reality, the process of identifying risk reflects a decision moment, which depends on the decision maker's attitude, the production process used as the basis and the characteristic features of the decision problem (Tischof et al., 1984). Those factors affect the two-step process of defining risk; in the first step, you must define which consequences or outcome dimensions are included; the next step is the construction of risk indicators based on the consequences selected in phase one.

According to Bernstein (1995:11), "in a world where changes come faster than what one could comprehend, risk seems to be less accessible from the aspect of measuring it than most investors would believe. As a result, the usual and reliable methods of risk management get into the defensive, so risk aversion becomes more intensive than ever before. On the other hand, there is an upsurge of demand for new products involving risk (investment alternatives), so deriving from the two efforts, markets become riskier rather than less risky."

\section{THE PREHISTORY OF RISK AND UNCERTAINTY IN ECONOMICS}

Economics did not exist as an independent branch of science, when Daniel Bernoulli's work (1738) laid down the fundamental theory of human decision making in the presence of risk, which is regarded today as the beginning of the theory of risk aversion and expected utility. Although Adam Smith's seminal publication (1776) is regarded as the first work of economics, it is usually not related to risk. That is so, although the book included a major reference to risk (Sakai, 2018:8).

It can be said in general that in classical economics the concept of risk was still mysterious for thinkers. Risk, hazard, uncertainty and chance rarely appeared in handbooks as synonyms. Adam Smith offered the following definition for the concept of risk:

"The revenue... derived from stock by the person managing or using it is called profit. If derived by a person who does not use it but rents it to somebody else, it is called interest (...) Part of this profit is naturally due to the borrower, who takes the risk and bears the damage derived from use, another part is due to the creditor, who allows the borrower to realise profit" (Smith, A., 1956; 1776:55).

Briefly: profit (and loss) tends to be higher on risky markets, while it is a fact that those markets attract many investors and that is why

"competition would soon be so great as to sink very much their pecuniary reward” (1776:117). 
Sakai (2018) remarks Smith failed to go into details of his considerations, but they are still sufficient to demonstrate how in Smith's perspective risk attracts the element that verifies part of the entrepreneur's income. Because people are willing to accept risk, the profit from risky activities will become lower.

Referring to entrepreneurs, David Ricardo observed the consequence of profit reduction:

“Entrepreneurs' motive for accumulation would diminish with every diminution of profit, and would cease altogether when their profit were so low as to afford them an adequate compensation for their "trouble" and "risk", which they must encounter in using their capital productively (Ricardo, 1821: 123).

John Stuart Mill paid more attention to the concept of risk examining its relationship to profit:

"The rate of profit greatly exceeds the rate of interest. The surplus is partly compensation for risk. An individual by lending his capital, on unexceptionable security, he runs little or no risk. But if he embarks in business on his own account, he always exposes his capital to...danger of partial or total loss. For this danger he must be compensated" (Mill, 1885: 406).

The above theoretical contributions are sufficient to say there was agreement in classical economics regarding the nature of profit and the related entrepreneurial risk. Accordingly, risk was able to justify at least in part the existence of the (positive or negative) difference between the market price and the cost of goods.

In the 1870 , the classical school of economics had to face a challenge by a new approach in the theory of economics: marginalism. The paradigm was transformed following a path of regarding risk at a variance from the classical one. Examining the function of entrepreneurs, Menger wrote the following:

“...I cannot agree with Mangoldt who designates "risk bearing” as the essential function of entrepreneurship in a production process, since this "risk" is only incidental and the chance of loss is counterbalanced by the chance of profit" (Menger, 1871: 161).

Roggi-Ottanelli (2013) underline that in the world of the thinkers of the marginalist school there remained little room for risk and uncertainty. Marginalist economists did not really pay attention to considerations of risk and uncertainty. Knowing that including risk and uncertainty in their models might lead to negative consequences, marginalists bypassed the problem by transferring risk and uncertainty among simple assumptions. 


\subsection{A turn in the management of risk and uncertainty in economics: Knight and Keynes}

Classical thinkers overestimated the stability of the market including areas where the results were clearly uncertain and where the economy and decision making were not controlled by deterministic or causal laws. That is where the works by Knight (1921) and Keynes (1921) represented a major turn. According to Knight (1921), risk and uncertainty can be differentiated as follows:

"To preserve the distinction...between the measurable uncertainty and an unmeasurable one we may use the term "risk" to designate the former and the term "uncertainty" for the latter The practical distinction between the categories of risk and uncertainty is that "risk applies to situations where we do not know the outcome of a given situation but can accurately measure the odds" (either because of preliminary calculations or statistics of past experience), "Uncertainty, on the other hand, applies to situations where we cannot know all the information we need in order to set accurate odds in the first place" usually because we cannot group the events as the situations involved are highly incidental. (Knight, 1921: 233-234).

Unlike risk, uncertainty was a fundamentally different concept in the sense it was not measurable. That unmeasurable phenomenon was nothing but "genuine uncertainty". As the main topic of his book, Knight (1921) created the core of Knightian economics: uncertainty was a key concept for understanding the effectiveness and limitations of market economy. Knight expressed his regrets because unmeasurable uncertainty had been neglected in economics before. Sakai (2018) underlined that as uncertainty was applied on real situations, its features needed to change. A new emerging type of productive man appeared. That individual was termed an entrepreneur who had a foresight in an unpredictable world. Then he undertook some brave action, which could result in extra profit if his predictions proved accurate.

Knight (1921) believed uncertainty was a necessary precondition for the existence of profit. He thought if the future was simply risky, no profit could exist. Two quotations from his book support the above interpretation:

"It is this true uncertainty which...explains profit in the proper use of the term...that of a pure residual income, unimputable by the mechanism of competition" (Knight, 1921: 20).

Knight continues as follows:

"Now since risk, in the ordinary sense, does not preclude perfect planning... such risk cannot prevent the complete realization of the tendencies of competitive forces, or give rise to profit (Knight, 1921:20). 
According to Knight, profit is a residuum: payment for the factor of economic activity, a reward for taking risk realised in proportion to the size of the risk taken. Accordingly, although the total income obviously cannot be known in advance, profit must always be regarded as a reward for a measurable function or act.

In Knight's view, subjective probabilities have no part to play with respect to the difference between risk and uncertainty:

"Business decisions... deal with situations which are far too unique, generally speaking, for any sort of statistical tabulation to have any value for guidance" (Knight, 1921: 231).

Knight perceived: it is not at all obvious that similar events may support an "objective" probability. He wrote about the uniqueness and categorisation of events as follows:

“...Nothing in the universe of experience is absolutely unique any more than any two things are absolutely alike. Consequently, it is always possible to form classes if the bars are let down and a loose enough interpretation of similarity is accepted." (Knight, 1921: 227) .

It is no accident Knight was of two minds as to how events could be categorised. On the one hand, he accepted that repeated actions could be grouped and rated based on probability, but he emphasised uniqueness with respect to business decisions.

In the age when Knight discussed risk and uncertainty, a separation of ownership and management was typical in the earliest phase only. Knight recognised the same factors that hinder the security of an enterprise are at the same time the cause of the problems, i.e., that stockholders employ paid managers to operate their enterprise. According to Le Roy-Singell (1987: 395), it meant Knight perceived that capital operators had been separated from owners, but he did not get to formulating the principal-agent problem, on the contrary, he denied the two had separated. This is proved by Knight's relevant opinion:

"There is an apparent separation of the functions of making decisions and taking the "risk" of error in decisions. The separation appears quite sharp in the case of a hired manager... Yet, a little examination...will show that the separation is illusory; when control is accurately defined and located, the functions

3 KNIGHT's doubts are reflected in the following quotation: "The distinction here is that there is no valid basis of any kind for classifying instances. This form of probability is involved in the greatest logical difficulties of all, and no very satisfactory discussion of it can be given, but its distinction from other types must be emphasized and some of its complicated relations indicated" (Knight, 1921:225). 
of making decisions and assuming the responsibility for their correctness will be found to be one and indivisible." (Knight, 1921: 293-294).

"Whenever we find an apparent separation between control and uncertaintybearing, examination will show that we are confusing essentially routine activities with real control." (Knight, 1921: 298).

Knight's rejection of the idea that paid managers essentially practise entrepreneurial functions is arguable, since in large corporates the representatives of owners and creditors delegate a significant part of their power to paid managers. That was less evident in Knight's age, but it is today.

Knight's teachings about uncertainty, and his finding that uncertainty provides sense to all economic actions was not only rejected in the age it was formed, but it was not fully accepted by eminent thinkers of later ages either. In that regard, it is worth recalling the words of Hirshleifer-Riley (1995) at the end of the 2oth century:

"The approach here does not allow for the psychological sensations of vagueness or confusion that people suffer in facing situations with uncertain (risky) outcomes. In our model the individual is neither vague nor confused. While recognizing that his knowledge is imperfect, so that he cannot be sure which state of the world will occur, he nevertheless can assign exact numerical probabilities representing his degree of belief as to the likelihood of each possible state. Our excuse for not picturing vagueness or confusion is that we are trying to model economics, not psychology." (1995:7).

Knight's stance on probability was special and complex: it was placed somewhere between the subjective and the objective theory. He believed the concept of probability was basically different in social sciences from that applied in natural sciences. Keynes' discussion surpassed this and offered a concept of uncertainty causing a major challenge. In his opinion, uncertainty is not simply unquantifiable and non-comparable as probability, but it is also a "wild concept" including the "animal spirits", i.e. spontaneous optimism (Cf: Marchionatti, 1999).

According to Jeronimo (2014:3), "in an effort to emphasise irreducible uncertainty and the volatility of expectations, particularly those related to the expectations of others, Keynes introduced (mostly undetermined) the concept of "animal spirits", an idea that was not received with much enthusiasm in the age. Animal spirits "seemed a diabolus ex machina - an artificial element introduced to make the story come out wrong" as explained by Koppl (1991:204.) Still, for Keynes, animal spirits (the state of consciousness, instinct, belief, coercion) "are a spontaneous urge to action rather than inaction, and not as the outcome of a weighted average of quantitative benefits multiplied by quantitative probabilities" (Keynes, 1936:161). 
Using modern wording, Keynes' view was the big leap is whether situations of decision making are managed characterised by uncertainty, or as a situation that involves risk only. Any choice of a future alternative is fundamentally uncertain as the future is logically unknowable. There are no samples from the future available, which would allow to learn the probability of future alternatives, therefore the uncertainty problem cannot be reduced into a problem including risk, as Weintraub states (Weintraub, 1975:532).

Keynes states uncertainty in traditional theoretical situations was examined using a method of probability suitable for the management of risk. In the traditional theory it was assumed you could maximise expected payments although expected values could not be calculated in a reliable manner. Individuals must act today, while their choices will only be known in the future. However, all economic actions happening at a given time have intertemporal consequences. An economic individual must base their decisions on something; it is either the immediate past or what others are doing. However, Keynes is critical of that framework condition of choice: "...being based on so flimsy a foundation, it is subject to sudden and violent changes” (Keynes, 1937:214).

Keynes justifies the importance of probability in decision making as follows:

"The theory can be summed up by saying that, given the psychology of the public, the level of output and employment as a whole depends on the amount of investment...(although some other factors may also affect output) I put it in this way, not because this is the only factor on which aggregate output depends, but because it is usual in a complex system to regard as the "causa causans", that factor which is most prone to sudden and wide fluctuation." (Keynes, 1937:221).

According to Keynes, "the necessity for action and for decision compels us as practical men to do our best to overlook this awkward fact. Expected values are calculated assuming that future output is derived from a stable distribution of returns. Individuals are aware that the distributions are not fixed, still - lacking a better choice - they behave exactly as we should if we had behind us a good Benthamite calculation of a series of prospective advantages and disadvantages, each multiplied by its appropriate probability, waiting to be summed" (Keynes, 1937:214).

Keynes (1921: Chapter 8) rejected the theory of relative frequency, because:

"if we allow it to hold the field, we must admit that probability is not the guide of life, and demanding it we are not acting according to reason."

As opposed to the above, Keynes stated probability is not the balance of advantageous and disadvantageous proofs, but: 
"the balance of absolutely relevant knowledge-mass and relative ignorance, and access to new proof increases the weight of the argument. The new proof may decrease the probability of an argument, but it always increases its weight” (Keynes, 1921:28).

Keynes was highly interested in the risk of investments from the beginning and presented this opinion on it in an early article (Keynes, 1910):

"As the risk to be considered is subjective risk, a feeling that, say, is of the investor, and its measure highly depends on the mass of relevant information on the investment accessible to them. What would seem a risky investment for an uninformed speculator may be exceptionally safe for a well-informed expert. The measure of risk from any investor's aspect basically depends on the degree of their information regarding the circumstances and outlooks of the investment examined" (Keynes, 1910:46).

Keynes states future return on investment cannot usually be attained as initially expected. According to Keynes, the knowledge shaping the basis of actual decisions is usually quite narrow. He proposes, "to be guided to a considerable degree by the facts about which we feel somewhat confident, even though they may be less decisively relevant to the issue than other facts about which our knowledge is vague and scanty." (Keynes, 1936:148). Those facts enter as investors fall back to the ground of conventions:

"The essence of this convention... lies in assuming that the existing state of affairs will continue indefinitely, except in so far as we have specific reason to expect a change." (Keynes, 1936:152).

Runde (1990:289) quotes Keynes' opinion on assessing the Benthamite method as a mistake; that was reflected in Keynes' renowned "Galton Lecture” (1937).

"Though it was... an ingredient in the complacency of the nineteenth century that... they accepted an extraordinary contraption of the Benthamite school, by which all possible consequences of alternative courses of action were supposed to be attached to them, first a number expressing their comparative advantage, and secondly another number expressing the probability of their following from the course of action in question, So that multiplying together the numbers attached to all the possible consequences of a given action and adding the results, we could discover what to do. In this way a mythical system of probable knowledge was employed to reduce the future to the same calculable status as the present. But even today I believe that our thought is sometimes influenced by such pseudo-rationalistic notions" (Keynes, Galton Lecture, 1937:124).

One can state of the Knight - Keynes turn that, on the one hand, Knight believed risk and uncertainty must be separated in an emerging system where total certainty 
no more prevails. He focused attention to the fact that decision makers must consider the impact of future events and they cannot simply rely on past occurrence when identifying future events.

Keynes, on the other hand, neglected the term "events" preferring statements instead, which place the emphasis on future events. He was adamant in opposing the mathematical analysis of past events and the use of their results for economic decisions Keynes' economic theory fully focused on uncertainty. He criticised analysis based on events and welcomed prediction based on statements. Keynes said probability had no impact on the occurrences of real life, simply because - although similar events occur repeatedly - there is no guarantee they can be observed in the future.

Both Knight and Keynes made efforts to rectify the shortcomings of earlier theories regarding the part played by risk in economic systems. Their new concept on uncertainty was an effort to change the prevalent views of their times, i.e., risk was not related economic decision-making. Chapman (2019: 5) underlined Knight's and Keynes' achievements because they presented the possibility of the vulnerability of decision making due to the factor of surprise. According to Keynes, a system that cannot be based on the frequency distribution of past occurrences is extremely vulnerable with respect to surprise and so it becomes volatile.

A specific transition from the classical school to the Knight and Keynes' model is presented by Haynes (1895). In his article he makes a difference between "risk which would be found in a stationary state of society" (p. 412) and dynamic risk ("risks of damage which may be directly due to dynamic changes)" (p. 412). ${ }^{4}$

\subsection{Principles of decision makers' risk taking}

The theoretical roots of risk taking, and risk bearing must be revealed and the origin of entrepreneurial risk must be found to clarify the part played by risk in economics and in the life of corporates. Keynes' characterisation of entrepreneurs described earlier is closely related to the analysis of entrepreneurial behaviour by Marshall and Schumpeter in his book, Marshall (1890) identifies entrepreneurs as people selected in the struggle for survival: "suitable/able people helped by good fortune" (Marshall, 1890:15) having the following qualities:

“...alertness, inventiveness and ready versatility” (Marshall, 1890:305);

4 "Static risks tend to diminish with progress, but the subjective estimates of risks in general and the number and magnitude of dynamic risks will tend to increase" (HAYNEs, 1895:449). 
"broad faculty of judgement, promptness, resource, carefulness and steadfastness of purpose" (Marshall, 1890:312).

An entrepreneur will get

"opportunities for bold but wise and profitable adventure" (Marshall, 1890:601).

Schumpeter writes that in business life

"the success of everything depends upon intuition, the capacity of seeing things in a way which afterwards proves to be true, even though it cannot be established at the moment" (Schumpeter, 1934:85).

Schumpeter emphasises the fundamental characteristics of entrepreneurs are that they are people who can look behind the usual channels, who have intuition and ability to adjust the predictions of future trends without having a suitable information base.

According to Schumpeter, an entrepreneur's motivation corresponds to the Keynesian specification of 'animal spirits', i.e., a 'non-rational factor' inducing entrepreneurial action in order to make an investment (Marchionatti, 1999:431).

According to Hicks (1931:174), there is a chance of a business going completely bust together with its inherent and operational resources; the chance of a lesser failure is varied, at the same time, success has every kind of chances. The 'pattern' of chances depends on the production technology applied, the size of the operation, and although it is unlikely they are selected considering their inherent risks, it is clear, that by changing them, the business may be able to change, to a certain degree, the risk taken. We can find that the head of the business is hesitant which method of production to choose - one is more efficient, but it is also riskier. Sometimes it is worth giving up some efficiency for higher security.

You can perceive that Hicks is talking about 'the reduction' of risk in his article, while Knight was writing about the elimination of risk. Knight's 'measurable risk' doctrine was the part of his teachings Hicks could not accept in any form without a compromise as it was first formulated by Knight (Knight, 1921:43).

5 It is worth making a short remark concerning Hicks' criticism of Knight. KNIGHT, (1921:43) in the section cited discussed the eliminability of risk in one context only, i.e., related to insurable risk, as follows: "It is admitted that the entrepreneur may get rid of risk in some cases for a fixed cost, by means of insurance. But by the act of insurance the businessman abdicates so much of his entrepreneurship, for it is manifest that an entrepreneur who should eliminate his risks by means of insurance would have left no income at all which was not resolvable into wages of management and monopoly gains. To the extent to which the businessman insures, he restricts the exercise of his peculiar function, but the risk is merely transferred to the insurer, who by accepting it becomes himself an entrepreneur and the recipient of an un-predetermined residue or profit. The reward of an insurer is not the premium he receives, but the difference between that premium and the loss he eventually suffers." 
Following the opinion of the thinkers of behavioural economics, it has become accepted that there is an inverse relationship between perceived risk and presumed benefit, and it is connected to an overall assessment of an individual with respect to gambling. If people like an activity, they are willing to assess its advantages as high but its risks as low. And if they do not like an activity, the assessment will be the other way round: advantages will be perceived little but the risk high (Kahneman-Tversky, 1979)

If, thanks to its introduction, a thing seems to be positive, individuals are more likely to stay with the positive aspect of the decision, and vice versa. It has been proved that experts are not immune to the framing effect, either. In the same way, logically equivalent but still different ways of summing up information related to risk may lead to different interpretation and different decision-making preferences (Tversky-Kahneman, 1981; Rabin-Thaler, 2001. Kovács, 2020).

Liles (1974) has found that individuals risk their financial well-being, career opportunities, family links and spiritual harmony when they become entrepreneurs. Personal financial obligations created by an entrepreneur in a failed enterprise cause the entrepreneur higher loss than for an individual, crippling not only their future lifestyle but also their business perspective. Further, since entrepreneurs devote themselves to their enterprise in a personal sense, the failure of the entrepreneur becomes, in fact, the failure of the individual, which may have important rational consequences. Recognising that the financial and emotional consequences of failure may have a devastating effect, Liles suggests that a potential entrepreneur should carefully analyse the risks linked to a specific business proposal and then to decide if they are willing to enter into the business or not.

Liles has found the decision greatly depends on the potential entrepreneur's perceptions about the risk inherent in the enterprise. Since Mill (1878), the literature on enterprise has included risk bearing as a major distinctive feature between managerial and entrepreneurial functions. According to Brockhaus (1980:513), entrepreneurial risk can be broken down to three components: the general risktaking willingness of the potential entrepreneur, the expected consequence of failure and the perceived probability of failure related to a specific entrepreneur. Willingness for risk taking can be defined as the expected probability of obtaining reward linked to the success of a planned situation, which is the reward an individual expects before submitting themselves to the consequence of the risk linked to the enterprise. An alternative situation provides less reward and entails less disadvantageous consequence than the planned situation. Such a definition could be the best description of the situation a potential entrepreneur is faced with when they decide about setting up a new business enterprise. 
Keynes (1936) identified two phases of capitalism based on the observations of the markets and business psychology. One is an old-fashioned capitalism, where - according to Keynes,

"enterprises were mainly owned by those who undertook them or by their friends and associates" (Keynes, 1936:150),

i.e., where ownership and company management are not separated,

"investment depended on a sufficient supply of individuals of sanguine temperament and constructive impulses who embarked on business as a way of life, not really relying on a precise calculation of prospective profit" (Keynes, 1936:150).

So, entrepreneurial activity can be assumed to have a specific mixed character, which reminds one

"business men play a mixed game of skill and chance... if [they] felt no temptation to take a chance, ...there might not be much investment merely as a result of cold calculation." (Keynes, 1936:150)

The other is mature capitalism, where ownership and management of a company are separated and where an organised investment market and the decisions on investments in effect depend on the expectations of stockholder investors. (Marchionetti, 1999:420) recalls Keynes' opinion (1937), saying “the value of investments on organised markets depends on others' judgement" (Keynes, 1937:213).

On investigating the theoretical bases of risk taking the question arises if there is a connection between interest, impatience and risk-taking willingness; and the question is closely related to the quantifiability of risk. The early history of investigating that problem led to Irving Fisher's basic work (1930). The opinion of that great thinker with respect to the quantification of risk is unambiguous:

"While it is possible to calculate mathematically risks of a certain type like those in games of chance" (classical probability) "or in property and life insurance where the chances are capable of accurate measurement" (probability based on relative frequency), "most economic risks are not so easily measured. To attempt to formulate mathematically in any useful, complete manner the laws determining the rate of interest under the sway of chance would be like attempting to express completely the laws which determine the path of a projectile when affected by random gusts of wind Such formulas would need to be either too general or too empirical to be of much value." (Fisher, 1930:316).

Accordingly, one can say Fisher has rejected the probability measurement of risk. His basis for conclusion was less specified than that of Knight, but his message was the same as that of the well-known reference classes and the law of large numbers. 
In addition to the quantifiability of risk, another open issue is the relationship between impatience and risk taking, which has not been discussed in the literature in depth. Time preference is a key concept of Fisher's interest theory (1930). According to Fisher, time preference or impatience is a psychological term. It either expresses that the goods of today are preferred over future ones, or the other way round: future goods are preferred over the ones of today, or that there is no preference either way. Balgah-Buchenrieder (2012:33) calls attention that Fisher connects impatience to risk taking.

"...The degree of impatience is the preference for, say, USD1oo worth of this year's income over USD10o worth of next year's income even if the total income, except for one dollar, is uncertain" A person's time preference, or impatience for income, therefore, depends theoretically on the size, time shape, and probability of this entire collection of income elements" (Fisher, 1930:71).

Since income has both a psychical and physical dimension, the conversion between present and future goods (i.e. the interest rate), in accordance with the conventional price theory, necessarily depends on the comparative marginal attraction of the psychological or the subjective component. For illustration, Fisher (1930: 72) writes the following:

"In general, it may be said that other things being equal, the smaller the income, the higher the preference for present over future income."

Accordingly, with respect to risk taking, you need higher income, since wealth is expected to be negatively correlated to risk taking, which results in stronger risk aversion.

In general, two dimensions of risk are identified, objective and subjective risk. In the case of objective risk, risks are estimated based on the quantitative measurements of past and potential future occurrences. On the other hand, subjective or perceived risk is the way decision makers anticipate future events in the knowledge of past occurrences. Uncertainty is used to express the subjective aspects of risk, which cannot be quantified. In Fisher's view, both risk and uncertainty, i.e. the objective and the subjective factor have an impact on decision making.

Impatience as a critical factor studied by Fisher is affected by both risk and uncertainty. Fisher indicated the level where the uncertainty of anticipated income affects the relative assessment of present and future surplus, where both increments are certain and can be identified. Therefore, the impact of risk on impatience is limited with respect to the future the risk relates to. Provided the future is risk free, the players being patient has a higher probability. On the other hand, if you do not sufficiently calculate with future risk and uncertainty (among others, wars or natural-health shocks), impatience will grow. Fisher indicated this as follows: 
"Some persons who like to take great speculative chances are likely to treat the future as though it were especially well endowed and are willing to sacrifice a large amount of their exaggerated expectations for the sake of relatively small addition to their present income." In other words, their impatience will be of a high degree. "The (same) individuals, if receiving an income which is risky for all periods of time alike, might, contrary to the rule, have as a result a low instead of a high degree of impatience" (Fisher, 1930:79).

Balgah-Buchenrieder (2012:34) underlines Fisher's finding, i.e. future income is always exposed to a certain degree of uncertainty, which affects the degree of impatience. The level of risk is defined by the future the risk relates to. If institutional framework conditions guarantee minimum security and certainty of the future defined in any way, the certainty of future wealth may reduce the actual degree of impatience.

Surprising parallelisms can be demonstrated between the sensitivity of perceived risk tolerance and perceived patience with respect to delay time, and also to assessment time. Postponing payments to the distant future makes people more tolerant of risk and more patient at the same time, and one-off assessment will have a positive impact on risk taking and time discounting behaviour. Epper-Fehr-Duda (2018:6) rightfully poses the question: since effects do not seem to be arbitrary disorders compared to the predictions of existing models, is there a common controlling mechanism directing not only delay and process-dependence but also timing, risk and other dependencies. The authors' answer is affirmative.

In Keynes' opinion, the coexistence of the two types of ownership and management makes business activity a mixture of enterprise, stock market assessment and speculation. As far as possible, an enterprise is based on credible calculation supported by a specific 'view on life', 'spontaneous optimism' creating chances using temptation and satisfaction with the help of the 'animal spirits'. On the other hand, investment activity is primarily controlled by traditional judgement. Accordingly, business behaviour becomes a mix of reliable calculation, conventional judgement, and the animal spirits. Businessmen's motives are identified by "habits, inclinations, preferences, wish and will" (Keynes, 1979:294). On the other hand, there is a long-term trend both in continuous business operations and investment decisions to preserve the unity of risk taking, risk bearing and responsibility for risk. 


\subsection{Attempt to re-interpret "animal spirits" as the intention for risk taking}

In Chapter 12 of his core work, Keynes (1936) wrote that under true uncertainty, entrepreneurs' long-term expectations on investment are not only defined by cold calculation. Instead, decision making relating to future action is defined by animal spirits - spontaneous optimism or urgency of action - as well as non-rational motives such as habits, inclination, preference, wish, will and passion that can be supplements or, what is more, replacements to the probability calculation of benefits. ${ }^{6} / 7$

Fontana- Marchionatti, (2007:1) believe the view was shared by few among the post-Keynesian thinkers of economics. On the one hand, it was interpreted as irrational and psychological motives were outside economic theory. On the other hand, if they had been included in economic analysis, long term expectations should have been regarded as exogenous factors, something that has a wholly arbitrary impact on economic behaviour ${ }^{8}$

Ever since the concept appeared ${ }^{9}$ it has been clear that animal spirits is a phenomenon that cannot be fully analysed using economic categories and no positive theory of it has been presented either. Dow-Dow (2011:1) state that animal spirits

6 'Animal spirits' was in the category of neglected concepts for a long time, and it was in effect excluded from scientific considerations. That was typical of most Keynesian economists except for the works of post-Keynesian authors. Joan Robinson (1962) regarded animal spirits as a functional concept; GEORGE SHACKLE (1967) and PAUL DAvidson (1991) underlined the part played by animal spirits as a proof of the essential irrationality of investment decisions.

7 According to SAKAI (2018), Keynes was the first to use the term 'animal spirits' and analysed its consequences in economics. He stressed of Keynes' opinion that you must make a distinction between instability owing to speculation and instability originating in human nature or spontaneous optimism. While the former is linked to mathematical expectations or quantified probability, the latter is related to true uncertainty, which cannot be measured and is incomparable.

8 Animal spirits have been given much attention recently as AKERLOF-SHILLER published their book (2009). The authors had the following to say in the Preface: "To understand the economy then is to comprehend how it is driven by animal spirits. Just as AdAm Smith's invisible hand is the keynote of classical economics, Keynes' animal spirits are the keynote to a different view of the economy - a view that explains the underlying instabilities of capitalism" (AKERLOFSHILler, 2009, Preface P.ix).

According to Dow-Dow (2011), the context the authors used to approach the concept was behavioral economics, which uses both psychological theory and neuroscience to help economists understand actual behaviours observed in experimental situations. Particularly to understand the aspect and to predict the behaviour which seems to be challenging the prediction of models built on the axioms of rational behaviour of individuals.

9 Mattews (1984:212) remarks that animal spirits already appeared in Hume's Human Nature (1739:318-319) in the form of 'my animal spirits orientation and passion'. 
was an element of critical importance among the framework conditions of decision making under uncertainty, which was a rational and acceptable argument in the wider sense. $.^{10} / 11$

To understand the post-Keynesian understanding of animal spirits, one should recall the original intention. Keynes (1936) used the category three times on pages $161-163$ of his book where he was discussing entrepreneurs' real capital investments:

"Most, probably, of our decisions to do something positive, the full consequence of which will be drawn out over many days to come, can only be taken as a result of animal spirits - of a spontaneous urge to action rather than inaction, and not as the outcome of a weighted average of quantitative benefits multiplied by quantitative probabilities...thus if the animal spirits are dimmed and the spontaneous optimism falters, leaving us to depend on nothing but a mathematical expectations, enterprise will fade and die, - though fears of loss may have a basis no more reasonable than hopes of profit had before" "But individual initiative will only be adequate when reasonable calculation is supplemented and supported by animal spirits, so that the thought of ultimate loss which often pervades pioneers, as experience undoubtedly tell us and them, is put aside as a healthy man puts aside the expectation of death" (1936:161-162).

The literature of economics regard animal spirits as a residual factor necessarily including irrationality and randomness Fontana-Marchionatti, (2007:3) think 'spontaneous urge for action instead of non-action in Keynes' concept can be broken down into two components. The first has a general impact as it influences the behaviour of all economic players. The interpretation of present and future predictions is conditioned sometimes (using Keynes' words), 'the waves of irrational psychology and emotions depending on nerves and hysteria'. Per definitionem, this part of animal spirits evades systematic handling. The second, spontaneous optimism is related to entrepreneurs' features represented by the tradition of Marshall and Schumpeter. In Keynes' words, 'individuals with a sanguine temperament and constructive impulses appear in business life as lifestyles. Spontaneous

10 The Oxford English Dictionary offers the following under 'Animal spirits', (i) the supposed agent responsible for sensation and movement originating in the brain and passing to and from the periphery of the body through the nerves, (ii) physical or animal courage (III) nervous vivacity, natural liveliness of disposition, healthy physicality, "animalism".

11 In the literature analysing the meaning of animal spirits there was a debate whether Keynes could be relying upon Descartes' remark on the topic when he offered the phenomenon. Lacking a formal citation, the debate between Koppl (1991) and MogridDge (1992) remained unsolved. The spirit suggested by the concept does not exclude Keynes' reliance on Descartes. 
optimism is the feature that differentiates entrepreneurs from other players of the economy: their willingness to engage in risky activities does not only depend on the balance of costs and benefits but it is a natural inclination to be committed to their company the outcome of the operation of which is uncertain. This natural willingness to bear the risk of investment plays an important long-term part in maintaining the level of investments and setting off the negative impact of limited information and uncertainty. It is an aspect of animal spirits one can build the positive theory of animal spirits on.

In Keynes' analysis, animal spirits are mainly linked to entrepreneurial behaviour. The part played by enterprises including the impact area of animal spirits has changed following structural changes in the production and service sectors. According to Gerrard (1994:16), as the management of companies by their owners somewhat diminished, the weight of business lifestyles was also reduced. Although Keynes focused his capital investment analysis on the individual owner-manager entrepreneur, and on the part of the money markets, aggressive entrepreneurial behaviour including animal spirits remained his theoretical basis. (Keynes, 1936:12.f.). It originates from the dependency of companies on share capital financing, when companies directed by owners had become publicly listed corporates. As a result, the valuation of investment plans by financial markets therefore put constraints on entrepreneurial activity even by large companies.

According to Dow-Dow (2011:11), managers of listed companies have moral responsibility to promote shareholders' interests and avoid excessive risk taking. So, the loss of moral responsibility has become a current issue in public discourse particularly because there have been several instances of violating the principle over the past decades.

One must pay particular attention to the separation of ownership and management because Keynes believed animal spirits indicated the inherent capacity or instincts/inclinations of entrepreneurs who can be characterised as 'old-style capitalists'. In Keynes' wording, 'they are individuals of a sanguine temperament who enter into business as a form of life' (Keynes, 1936:150). He also made it clear in those paragraphs that investments would be insufficient without the animal spirits. The reason why investment decisions rely on animal spirits is that rational quantitative calculation alone cannot justify action under uncertainty.

(Marchionatti, 1999:430) acknowledged if one could find economic factors systematically verifying the existence of animal spirits, one could say their analysis could be done as part of the theory of economics, and after that one could reject the alleged feature they were absolutely arbitrary, which drove many thinkers to reject animal spirits. 
There is a chance for that, as Keynes' core work (1936), regarding its spirit, allows for a wider interpretation of animal spirits. Keynes looked at the economy as an open, organic system, where creativity and evolutionary changes meant that the past had limited guidance relating to the future. According to Schakle (1972), changes in creative behaviour and social structures take place in a way that cannot be predicted based on quantitative probabilities. Institutions and the emerging social practice provide a more stable environment for decision making, but - as Keynes (1937:214) emphasised - reasons and proofs must be supplemented by other forms of (uncertain) knowledge: conventional knowledge, the knowledge of professionals and reliance on past experience. In addition to the above, Keynes (1936) wrote of animal spirits as follows:

“...Human decisions affecting the future, whether personal or political or economic, cannot depend on strict mathematical expectation, since the basis for making such calculations does not exist;...it is our innate urge to activity which makes the wheels go round, our rational selves choosing between the alternatives as best we are able, calculating where we can, but often falling back for our motive on whim or sentiment or chance" (1936:162-163).

Keynes' analysis indicates the relative importance of animal spirits is higher with some people as an inherent feature than with others, under certain circumstances and that is why he focused on the category in his discussion of entrepreneurial activity.

Marchionatti (1999:430-431) recognised the entrepreneurial option to follow the animal spirits cannot be regarded as a non-economic (or irrational) decision, instead, it seems to be something to be explained by references to the political, social or economic atmosphere. The context refers to the rules of the three areas and recalls an institutional background that is favourable for entrepreneurs. Changes there induce psychological response and explain the sudden changes in animal spirits and anticipations. The meaning of the atmosphere in an economic sense indicates a set of organisational and environmental factors using concepts established in economics and innovation, such as the age of a company or the intensity of competition.

One must also agree with the proposition by (Marchionatti, 1999:430-431) that Keynes' analysis of economic behaviour under uncertainty can be regarded as a general model that may include proofs as to the players making efforts to be rational both in their behaviour and in shaping their long-term expectations. Animal spirits in that context are phenomena that cannot be regarded as part of the theory of economics by its traditional principles, but they can be analysed with reference to the institutional and economic atmosphere. The first can be analysed by the psychological response induced by the changes in the institutional context; 
the latter refers to the motivation of innovative behaviour that is a factor in affecting long term economic progress.

Keynes thought it was important to assess the part played by conventions in the context of animal spirits, as he wrote the following,

"...if we can rely on the maintenance of convention, an investor can legitimately encourage himself with the idea that the only risk he runs is that of a genuine change in the news over the near future, as to the likelihood of which he can attempt to form his own judgement, and which is unlikely to be very large. For, if the convention holds good, it is only these changes which can affect the value of his investment, and he need not lose his sleep merely because he has not any notion what his investment will be worth ten years hence. Thus, investment becomes reasonably 'safe' for the individual investor over short periods, and hence over a succession of short periods however many, if he can fairly rely on there being no breakdown in the convention, and on his therefore having an opportunity to revise his judgement and change his investment, before there has been time for much to happen. Investments which are 'fixed'for the community are thus made 'liquid' for the individual. (Keynes, 1936:152-153).

According to Keynes, conventional judgement and animal spirits together can be interpreted as determinants of the rate of uncertainty or as verifiers of reliable calculation when confidence is low (Keynes, 1936:152-153). According to Gerrard (1995:191), animal spirits can be regarded, at least partly, as determinants of the state of confidence; confidence in itself 'is the weight available and can be assessed as the risk of error (Gerrard, 1995:191).

Dow-Dow (2011:11) confirms that “Keynes' use of the concept of animal spirits therefore goes beyond a relatively enduring characteristic of entrepreneurs alone and incorporates his notion that 'spontaneous optimism' may 'falter." If uncertainty increases because confidence in expectations declines, those involved refrain from active decisions. Dow-Dow (2011:11) underlines "Just as the degree of confidence can change by degrees, animal spirits can also be understood to change by degrees." So, while investment decisions can be regarded as a dual concept of action/non-action, a wider application of animal spirits would allow for degrees of action starting with liquidity preference through different degrees of conventional judgement to pure creative innovation.

As far as expectations are concerned, strong animal spirits take the form of spontaneous optimism, optimism which does not logically follow from reason and evidence. As far as the confidence in expectations is concerned, strong animal spirits take two forms: a low perception of uncertainty on the one hand and a high willingness to act in spite of whatever uncertainty is perceived on the other 
hand. Both are prone to changeability subject to circumstances. It means there may be structural factors encouraging entrepreneurs and boosting animal spirits separating them from the circumstances.

In line with the above, animal spirits are the middle link connecting reason and proof to decision making, which is true risk taking. Animal spirits are the breakthrough triggering the final push, and as such, the moment when risk is born. Animal spirits relying on spontaneous optimism are suitable for perceiving and ignoring uncertainty (as a limitation to act) as well as for increased willingness to act. So, animal spirits are linked to the uncertain knowledge underlying decisions, where confidence in changes is subject to the willingness to recognise uncertainty. In the same way as thinking and emotions are interrelated, animal spirits are also linked to other inputs of decision making. While conventions and routines represent a passive way of avoiding uncertainty, animal spirits are the active way of aversion. As a result, interactions between animal spirits and other contributions to decision making can be revealed.

Dequech (1999:420) presents animal spirits as 'optimistic willingness' to face uncertainty. If animal spirits are strong at a time when action is not supported by motive and proof, they can cause a breakthrough at a certain point. The opinion of Dequech (2011:18), is striking elsewhere, when he says animal spirits are in the subconscious; they are neither accidental nor subject to the necessity of a full-scale explanation; they are neither rational nor irrational, rather they are a-rational, i.e. an impulse not weighing rationality, they belong to the field of emotions rather than that of the intellect.

\subsection{Rational choice under the circumstances of risk and uncertainty - the Keynesian example}

In the first half of the 2oth century the theory of rational choice had become a core element of classical economics as described by Schirillo (2017:77), the evolution of the theory of decision making was regarded to be an anti-psychology development. New theoretical framework conditions have been set up; the process of rational choice has been deprived of all psychological and descriptive content using analytical processes and mathematical limitations. Rationality was constructed based on preferences or the consistency of choice, so individuals were regarded to be rational if they behaved in a coherent manner and their preferences were consistent. In other words, individuals are rationalistic if they are able to think clearly and to make decisions and pass judgements that are based on causality. As a result, economics and psychology were clearly separated. While the former had become 
part of the core of normative theories (how an individual must behave), the latter had become the field of studies in actual behaviour.

Rational choice under the circumstances of risk and uncertainty had been based on the concept of probability In the history of ideas the theory of probability developed as a rational approach to risk, and its thinkers implicitly assumed that individuals had to be allowed to behave rationally if faced with a risky decision. ${ }^{12}$

Investors always strive to achieve a good return on investment, so - as a trend they make investment decisions that are expected to yield profit. In theory, it is possible without considering the level of risk inherent in a given enterprise. According to Chapman (2019: 17-18), investors tend to place their bets on something they are certain about rather than simply speculating. A competitive environment creates uncertainty regarding the profit to be attained. In such situations many investors will deviate from the rational behaviour of striving for high return. Decision making is key to decide the level of profit to be achieved by some investment. The competitive environment of stock markets necessitates investors' caution in decision making. On the other hand, rationality must be the main goal to achieve maximum profit. Therefore, both rational and irrational behaviour must be considered as long as decisions provide maximum profit. It is clear then how risk defines investment decisions as it has a strong impact on rationality.

In the neoclassical tradition the criterion of rationality demanded utility to be maximised so that it was done without assessing the interactions linking an economic entity to other players. However, Neumann-Morgenstern (1944) reshaped the criterion. According to Roggi-Ottanelli (2013), an economic entity striving to maximise is, in fact, linked to an overall strategy that can consider potential synergies with other players. The discipline of game theory is built on the concept of 'strategic interdependence', as the results of actions by individuals greatly depend on the choices of others, therefore the optimum is based on emotions impacted by others' behaviour. Risk appeared in the context of game theory in a more specific way (with lower impact) as opposed to the traditional concept, which was not the consequence of the actions of the individuals every individual can interact with.

12 Marchionatti (1999:416-417) calls attention that in the neoclassical economics there is no basis to form a rational judgement if one is faced with true uncertainty. An idea by LucAs, (Lucas, 1981:224) "economic justification has little value in cases of uncertainty" has become dominant over the past decades. Assuming the neoclassical 'rational postulate', the only satisfactory way of shaping expectations is to apply Muth's (1961) model of rational expectations, which allows the introduction of endogenous expectations. The model of rational expectations assumes that expectations correctly identify the average and variance of stochastic variables impacting future dependencies, and so it solves the problem of erroneous belief of economic players relating to the future. 
Important decisions involve risk. So, it is no surprise that one is trying to understand how decision makers build risk into their choices. In effect, risk aversion has always played a major part in assisting the solution of economic problems in diverse areas such as insurance, contracting or the selection of portfolios (Arrow, 1971; Grossman-Hart, 1983; Markowitz, 1959). In the models of risky choice whether they are normative or descriptive one must assume that individuals assess risky perspective or the game of lottery by using some type of weighted average. Thus, relatively good outcomes must be balanced with the option of relatively poorer results (Gneezy-List-Wu, 2006).

In the classical treatment of decision making under risk, equilibrium can be captured in a formal way: the usefulness of the outcome is weighted with the probability of outputs occurring. Prospect theory also applies a weighted average scheme, where the utility of the outcome is weighted with a decision, which usually over-weighs low probabilities and under-weighs medium or high probabilities (Kahneman-Tversky, 1979; Tversky-Fox, 1995; Tversky-Kahneman, 1992).

As it is well known, individuals' decision making is difficult to model under risk and uncertainty. Instead, there is another train of thought to describe how individuals make their decisions. In this case the focus is on how individuals perceive and interpret risk and uncertainty, and what propensities impact their choices under risk and uncertainty. Park-Shapira (2017 underline an effort has been made to identify a risk attitude linked to personality and culture, which is a stable feature of individuals. (Cf the ideas of Douglas-Wildawsky, 1982). However, the lack of consensus and consistence of opinions suggest there is no potential connection between risk taking and propensity features (Slovic, 1964). In addition, there are other factors impacting risk taking. With respect to individuals' risk preferences, for instance, it has been found to depend on the framework conditions of the problem to be decided on (Tversky-Kahneman, 1981) and on the individuals' mood and emotions in the minute of the decision (Loewenstein et al., 2001).

According to Brockhaus (1980: 511), "performance level may be the highest when uncertainty about the outcome is the highest (when the probability of success is 0.50)". (This finding corresponds to Knight's profit theory discussed earlier.) The prediction might be true irrespective of whether the motive of achieving his goal or that of avoiding failure is stronger in an individual. However, an individual whose motive to achieve is stronger must prefer medium-size risk and, instead, prefer either safe realization of very low outcome or strive to avoid failure with much stronger motivation. This individual may tend to solve safe tasks or to explain the failure of solving a very speculative task without taking the blame.

Fontana-Marchionatti (2007) emphasise in their paper a basic theorem of Keynes' relating to expectations, i.e. long-term expectations depend on the most probable prediction to be made by the players and on the confidence in it. Since the knowl- 
edge of the future 'fluctuates, it is undecided and uncertain', one cannot make use of the probability theory of anticipations. Keynes writes the following about it:

"Generally speaking, in making a decision we have before us a large number of alternatives none of which is more 'rational' than the others, in the sense that we can arrange in order of merit the sum aggregate of the benefits obtainable from the complete consequences of each. To avoid being in a position of Buridan's ass, we fall back, therefore, and necessarily do so, on motives of another kind, which are not 'rational' in the sense of being concerned with the evaluation of consequences, but are decided by habit, instinct, preference, desire, will. ” (Keynes, 1979:294).

It is a very important fact with respect to our message that Keynes rejected that irrationality played a major part in explaining human behaviour under uncertainty, he emphasised,

"We should not conclude from this that everything depends on waves of irrational psychology." Keynes, 1936:162).

On the contrary, he recalled that human decisions have a limited information and cognitive base.

"...human decisions impact the future... and they cannot depend on strict mathematical expectations as making such calculations has no basis" (Keynes, 1936:148)

In line with Keynes, in a certain environment the decisions of economic players are justified to be subject to conventional judgements and to animal spirits as a supplement and support to rational calculation. The representatives of neoclassical economics have rejected that idea advising that rationality has little value under real uncertainty, as they believed the territory of irrationality alone exists outside the empire of rationality. Marchionatti (1999:434-435) has come to the same conclusion.

The problem is that although adapting the conventions can be a credible way of action under the given circumstances to make an investment, decision makers are still aware, that

"The actual results of an investment over a long term of years very seldom agree with the initial expectation" (Keynes, 1936:152). Since we "expect large changes but are very uncertain as to what precise form these changes will take, then our confidence will be weak" (Keynes, 1936:148). The predictions of their decisions and thus the state of their long-term expectations is prone to sudden revisions under the effect of sudden changes.

In his paper Keynes (1937) strongly distanced himself from the relevant theorem of classical economics, which was closely related to the approach to rationality: 
"...The theory we devise in the study of how we behave in the marketplace should not itself submit to market-place idols" (such as the Benthamite calculus). "I accuse the classical economic theory of being itself one of these pretty, polite techniques which tries to deal with the present by abstracting from the fact that we know very little about the future" (Keynes, 1937:215).

So, it is no surprise that Keynes' treatment of 'rational behaviour' in his papers on economics is not based on maximising expected utility. Unlike most modern economists, Keynes viewed the economic motive as one factor of many (Bateman, 1988; Lawson, 1986), and one usefully supplemented by an 'irrational factor', such as animal spirits, whim, foible, or similar ones. Keynes' conclusions and analysis are based on information surrounded by a specific social and economic context in which decision makers find themselves too. The implications of different time horizons result in different predictions as expressed by Runde (1989:289)

Following O'Donnell (1990), one arrives at a more sophisticated picture of the way Keynes treated rationality. He used arguments to describe the shift in emphasis that took place in Keynes' thinking from the mid-twenties. Without distancing himself from the theoretical basis of his work on probability, in Keynes' (1921) thinking the weight of weak rationalism increased while that of strong rationalism declined.

According to O'Donnell (1990, 259-260), "the key to the controversial issue of the rationality of economic players can be found in Keynes' core work (1936). It is not based on the neoclassical theory of rationality but on the theoretical principle in midway between the logics of probability and clear psychology, which derives from the non-neoclassical framework conditions of Keynes' work on probability (1921). It is no surprise that Keynes' theory on rationality was not welcomed by the thinkers of the neoclassical theory. ${ }^{13}$

Keynes made progress by drafting a novel theory of rationality under the circumstances of fundamental uncertainty and was open for improvement in a framework that was less restricting than the neoclassical theory. The way he rejected complete irrationality or clear psychology is worth attention, but he insisted that behaviour under extreme uncertainty can be linked to the core of rationality.

In essence, Keynes' view was that rational players act the best way they can under given circumstances. When they are in an environment where no credible infor-

13 One must remark that investment decisions are made on consideration of expected return. KAHNEMAN-TVERSKY (1981) made progress in the theory of risk aversion and as a result in decision making. They summarised their assumptions and proposals in their work 'Prospect Theory'. They challenged the rationality of human behaviour in decision making when decision makers were faced with different presentations of the same problem. In such a situation, investors are inclined to opt for an enterprise where loss may be avoided instead of avoiding risk. 
mation is available and the strong forms of rationality cannot be accessed, their decision-making circumstances are categorised among the forms of weak rationality, which situation may also include psychological motives. The Summary of Keynes' paper (1937) is a good example. After explaining irreducible uncertainty, Keynes turns to the investigation of rationality and behaviour advising that under the traditionally destructive forms of rationality

“...manage so that... save face as rational economic people" (Keynes, 1937:214).

It means that Keynes' opposition remained till the end, as O'Donnell (1990:254) expressed in the context of the ultra-rationality of omniscience.

\subsection{Two ways of canonising risk: maximising expected utility and portfolio optimisation}

Following the core works by Knight (1921), Keynes (1921) and Keynes (1936), the necessity to consider risk and uncertainty in investment decision making appeared in the ' 20 s and ' 30 s of the last century. The clarification of the theoretical background of risk taking, drafting the theory of rational choice and the strong emphasis on the part played by uncertainty by Knight and Keynes established a firm basis to adopt the function of risk and uncertainty in decision making. Risk and uncertainty could be included in the canon of economics along two paths, the maximisation of expected utility on the one hand, and on the other hand, by portfolio diversification.

Using expected utility for a choice under uncertainty goes back to the 18 th century. The Bernoulli theory (1738) had two branches: one was the law of big numbers, the other the inclusion of risk aversion in decision making under uncertainty. Such approach to decisions was closer to reality than calculations based on expected profit only. The paradigm of expected utility brought to light two things: one was the need to measure utility, the other the difficulty related to the repetition of experiments several thousand times to get closer to an estimation of the average of the random variable.

Neumann-Morgenstern (1944) stated uncertainty is based on others' knowledge or ignorance. Acting in that way, decision making strategies can be realised so that a connection is made on how others' efforts are linked to our intentions.

Uncertainty, the strategies of game theory and the theory of rational decisions affect the decisions made in economic systems. The theories have no regard to the preliminary assumptions of a system in which decision makers are assumed to have perfect prediction. The above three theoretical statements advise that risk is present in economic systems, which is another argument for considering them before decisions are made (Bernstein, 1998). 
Bernoulli hoped to settle the contradiction between expected value and individuals' payment willingness by replacing the expected value of payments with their expected utility in the solution. He took the moral value of the gain rather than its monetary value. As a result, individuals could make subjective decisions on their choice based on their subjective feeling of utility rather than based on rationality. Bernoulli recognised that the continuous growth of wealth by monetary units provides individuals with less and less joy as their well-being improves less and less. He expressed the relationship between wealth and utility as follows, "The utility resulting from any small increase in wealth will be inversely proportionate to the quantity of goods previously possessed". (Bernoulli, 1738, 1954:25). It indicates Bernoulli assumed individuals' behaviour of risk aversion, since that is why they reject a game offering theoretically infinite amounts of gain. ${ }^{14}$

According to Bernoulli, gain in a game increases utility but to a lesser degree than loss decreasing it. In consequence, many thinkers of economics have concluded that a willingness to take risks must be regarded 'irrational'; in other words, choice under risk or uncertainty was regarded suspicious or at least outside the terrain of economic theory, since economics assumed rational players. It might have been why Bernoulli's discovery was forgotten for a long time and got into the focus of interest in the middle of the 20 th century only. ${ }^{15}$

Individual choice has been studied by assuming the complete isolation of economic players ever since Bernoulli's work (1738). The choice of individuals may be analysed jointly with the members of the given social group, but all systematic approach that could have examined the interrelationships of many individuals lacked a strict economic principle.

Neumann-Morgenstern (1944) stated uncertainty is based on knowing or not knowing others' efforts. Acting in that way, decision making strategies can be realised so that a connection is made on how others' efforts are linked to our intentions.

14 As Bernoulli's St. Petersburg game has infinite expected value, the expected value of the related loss is also infinite. It is unacceptable for a sound mind to pay infinitely much to participate in a game. One would risk even a finite large amount of money with caution for the opportunity to reach very big gain if its probability is very low. So, the St. Petersburg paradox is based on the contradiction that the expected value of of the gain is infinitely large, but individuals are unwilling to pay much for the right of participation.

15 It is telling to recall KEYNEs' objection to the St.Petersburg game (1921:318-319), “...which strengthens the importance of Bernoulli's usefulness paradigm, “...if we have good fortune in the tossing, (partly) because we do not know what we should do with so much money....if we won it, partly because we do not believe we ever should win it, and partly because we do not think it would be a rational act to risk an infinite sum or even a very large finite sum for an infinitely larger one, whose attainment is infinitely unlikely". 
Uncertainty, the strategies of game theory and the theory of rational decisions affect the decisions made in economic systems. The theories have no regard to the preliminary assumptions of a system in which decision makers are assumed to have perfect prediction. The above three theoretical statements advise that risk is present in economic systems, which is another argument for considering them before decisions are made (Bernstein, 1998).

Maximisation of expected utility was introduced into the canon of economics through the work by Neumann-Morgenstern (1944). In it, the authors described a series of axioms relating to individual preferences and offered proof that provided an individual observes those axioms, they will follow the path of expected utility. As a result, the series of axioms establishes the structure of preferences. In a normative interpretation the axioms can be regarded as the teaching of rational choice and can be assessed by their normative attraction. In effect, if individuals fail to maximise their expected utility, they will violate some precise axiomatic principle observing which would have been absolutely necessary.

The theory of expected utility highly simplified the mathematical formalisation of the process of decision making while it omitted some important variables of the decision-making process, such as the complex nature of risk situations, or the limits of decision makers' cognitive resources (Schilirò, 2017).

Utility is a concept introduced to reflect considerations of risk in decision making and in assessing future events instead of decision makers taking steps based on the probability of expected value only.

The theory of expected utility cannot provide a credible explanation to consider risk aversion when stakes are modest, which caught the attention of several authors in different specific circumstances when discussing the different forms of utility functions. One is aware of Arrow's result of formalised barrier (1971), according to which maximisers of expected utility are (almost everywhere) close to risk neutrality when stokes are randomly low. Rabin (200o) presented a theory that the neutrality implication of expected utility is not restricted to specific contexts, special function forms or stakes that are negligibly small.

The theory of expected utility as a normative model of rational choice has raised doubts ever since its inception whether it can provide an explanation to actual choices (decisions). Allais (1953), for instance, questioned if individuals actually choose by linear weights of probability. Kahneman-Tversky (1981) found that individual choices change subject to how a problem is framed rather than based on its objective features. It seems obvious that both risk aversion and the trend to isolate each risky choice must be key components of a good descriptive theory of risk attitudes. 
At the same time, Starmer (2000) indicates that violations of the principle of expected utility are less frequent when all options are uncertain. The observation is particularly interesting if decisions of risk taking are regarded in their timeliness. Specifically, certainty and uncertainty are combined in inter-temporal decisions; the present is known and certain while the future is inherently risky. The observation is problematic if one wants to study time preference isolated from risk ( $\mathrm{An}$ dreoni-Sprenger, 2012). In the middle of the 2oth century Hicks (1931) stated before risk had been canonised by expected utility that individuals rather assessed risky alternatives based on the expected value of uncertain payments and other potential elements of the distribution than based on expected utility.

Decision making in uncertain situations is, in effect, a choice between outlooks/ outcomes. Theories based on expected utility serve the study of decision makers' risk attitude. Expected utility in the explanation of human decisions is different from expected return since rational decision makers rate different outcomes based on their utility subjectively perceived rather than by their monetary value. Neumann-Morgenstern's concept of expected utility means uncertainty has been built into the utility theory. They defined normative criteria which, if observed, result in the rational behaviour of decision makers. ${ }^{16}$.

In the neoclassical theory utility is expressed by preferences. The goal of a rational decision maker is to maximise utility. In this model individuals are fully informed, so they can make a choice under secure conditions. In the NeumannMorgenstern model individuals must decide under uncertainty. In that scheme the measure of utility is the expected value of utilities that can be achieved in different states of occurrence. Here individual preferences are the basic means of choice, so utility is used to manage preferences. Individuals' decisions under uncertainty do not only depend on what they can 'gain' but also on 'at what probability'. Decision makers' preferences do not only refer to outcomes but also to their probability and they monitor the items and results belonging to the final outcome only. One does not know which environmental state will occur in dif-

16 Abstract models in addition to being descriptive provide an explanation of the conditions required for a given state to be established. Thus, the key criterion of the validity of the model is the consistence of its inherent logics, 'theoretical cleanliness', secured by its axiomatic structure. Since it is presented hypothetically, the variables and parameters in 'ex ante' models are a priori and not experimental categories. So, its accuracy and empirical manageability are not necessary conditions of the validity of the model.

As the axiomatic method spread, the empirical-intuitive approach was temporarily suppressed as opposed to hypothetical-logical ones. Neumann himself called attention to the danger of that $(1937 ; 1965)$ saying if a mathematical discipline moves far away from its experimental sources, it is threatened by degeneration. 
ferent decision-making situations, but an individual knows the probability of the occurrence of all environmental states. ${ }^{17}$

Mentioning the latter limitations explains the necessity to establish a descriptive decision theory. Empirical studies of individual behaviour, which are increasing all the time, have identified several features of decision making that cannot be explained with the normative theory. According to Gneezy et al (2006), the theory of expected utility, the prospect theory and the other models of risky choice are based on the fundamental assumption that an individual's choice of one of risky prospects balances the value of potential consequences. Thus, the models must place the value of risky prospects between the highest and lowest value of the prospects.

Fontana-Marchionatti (2007) emphasises that in real life economics deals with variable and unstable factors, such as 'motives, expectations, and psychological uncertainties' in the context of limited knowledge and structural uncertainties, which makes the subject of analysis very complex. The lack of homogeneity over time forces economics to carry out inductive analysis. Corresponding to Keynes' opinion, no complete and accurate generalisation is possible due to the nature of economic matters.

Despite all reservations and criticism, one can view the Neumann-Morgenstern model as an important principle of choice under risk and uncertainty. According to the theory of expected utility, a parallel of a certain outcome (utility equivalent) that is neutral regarding uncertainty. can be found for all options of an uncertain outcome (asset position). It is the basis of the Neumann-Morgenstern utility function that defines the utility of different asset positions as the expected utility of an equivalent (neutral) event of uncertain outcome.

Markowitz's theory of portfolio diversification has been an important moment of canonising risk in economics. Thinkers that used Markowitz's theorem as a starting point to draft the concept of risky choice could make progress without the need to manage the difficult task of risk characterisation; they could simply adapt a ready-made explicit mathematical formula. It is interesting that in his milestone

17 If a decision maker's preferences satisfy the axioms (completeness, transitivity, continuity, independence), there is a linear utility function representing preferences, which is the sum of the multiples of the utility of outcomes and the relevant probabilities. This follows from the axiom of independence: the utility function is of a specifically additive structure with respect to different outcomes that cannot be predicted. One can say the profit of a gamble is the average of the profit of the outcomes weighted by the probabilities. The utility of gambling is expected utility, it is the expected value of the utility of the outcomes. Rational decision makers strive for maximum expected utility according to such utility functions. 
paper Markowitz (1952) did not offer a definition of risk. Instead, he proposed the following simple rule:

"an investor should consider: return is desired but the variance of return is something undesired” (Markowitz, 1952:77).

That is all Markowitz wrote and he did not mention that the variance of return would be the approximate rate of risk. He only remarked that risk is unwanted. He wrote the following at the end of the paper,

"the concept of return and risk often appears in papers on finance. Usually, if the term 'return' is replaced by 'expected return' and 'risk' by the 'variance of return', the meaning will somewhat change". ${ }^{18}$

Markowitz also stated if

"the variance of return on investment is used as a proxy for risk, little change of apparent meaning would result." (Markowitz, 1952:89).

Markowitz's paper (1952) emphasises rationality in decision making with the help of measuring risk and recommending an effective portfolio as solutions to minimise risk as an unwanted element. Using his model, investors can select the combination most suitable for them at a given moment by taking return as the basis. He describes investors to be risk averse. However, the opposite theory proposed by Kahneman-Tversky (1979) assumed investors were loss averse rather than risk averse as Markowitz said. If the same problem is wrapped differently, they will select the one offering a win.

It is obvious that investors regard risk as something that can be the source of either high return or a big loss, which drives some to be risk averse while others will be risk seekers. According to Markowitz, the concept of variance is definitely an unwanted element investors strive to minimise. Variance indicates the breadth of the band the return values of some assets fluctuate in around the average (Bernstein, 1998).

Markowitz introduced diversification ${ }^{19}$ to reduce volatility. It happened after he observed that most investors are risk averse. They strive to invest in low-return

18 This suggests that the variance of return could be the approximate rate of risk, although Markowitz was careful to distance himself from the association.

19 It is worth noting as a point of interest that, much before MARKowitz's diversification thesis, Keynes preferred the allocation of assets where investors' purses held the most popular securities only. "(As time goes on, I get more and more convinced that the right method in investment is to put fairly large sums into enterprises which one thinks one knows something about...) It is a mistake to think that one limits one's risk by spreading too much between enterprises about which one knows little and has no reason for special confidence... One's knowledge and experience are definitely limited and there are seldom more than two or three enterprises at any given 
enterprise even there would be options to invest in riskier projects in the hope of higher return (Chapman, 2019).

Before Markowitz appeared on the scene, the definition of risk had met the criteria of interpretation/management partially only; two more steps had been necessary. The first is the definition of variability as the standard deviation of return as Markowitz has done. The other, which has made the approach simple but effective, is to reduce investors' choices to two dimensions. The 'right' dimension can be regarded as the expected return of an investment, while the 'wrong' dimension is the variance or volatility of the return. There are two ways to justify the expected value variance focus: according to one, return values are of normal distribution, the other is to assume that investors will be forced by the utility function to focus on expected return and variance. As for the assumption of normal distribution, it is not simply systematic, but it can be characterised by the expected value and variance. If return values were of normal distribution, they would provide investors with a basis for variance with two variables. The problem of the assumption is that return values cannot be of normal distribution in the case of most investments. The worst possible outcome for an investment into stocks is the loss of all invested assets, which means a return of $-100 \%$ (and not $-\infty$, a requirement for normal distribution).

Bernstein (1998) was right to suspect that classical ideas about capital suffered from things like skew, excess kurtosis and other asymmetries. Non-linear hypotheses are criticised. Fears due to discontinuity are more pressing than the factors of pricing volatility, and they become irrelevant via the exotic new financial instruments arriving in unknown forms and hedging unknown risks. As the calculations defining such risks become more and more complex, the dimensions, the contours and the limit of risks become hazier and hazier.

The interpretation of downside and upside risk plays an important part in taking, perceiving and exposure to risk. Intuitively, downside risk must be important for decision makers instead of upside risk. In other words, there are few investments where the result is better than expected and its return is going upwards causing nervousness and worry. More often than not, the outcome of investments significantly differs from the expectations. In the expected variance framework,

time in which I personally feel myself entitled to put full confidence" '(Keynes' letter to F.C.Scott on 15 August 1934; Keynes, 1983).

Although according to Markowitz's theory an investor should invest into one fund of risky instruments only, i.e. the one which is the market portfolio in equilibrium, There exists important proof to suggest that rather than investing into a market portfolio investors should hold major sums in a few assets they know very well. (C.f. Warren Buffet's method of investment in the Berkshire Hathaway investment enterprise, BoyLE et al. (2010). 
similarly, weighing upside volatility and downside movements with no difference made between the two.

Unlike in intuition, in rational considerations the differentiation of upside and downside risk is irrelevant if the distribution is normal or otherwise symmetric, as the risks are equivalent. On the other hand, there may be a difference between upside and downside risk if the distribution is asymmetric. Studying people's risk aversion proves that pain due to loss has a bigger weight than joy caused by equivalent win. Individuals assess very large positive payments much higher than the probability they link to such payments. As mentioned above, the return of stocks and other instruments is not symmetric in practice. Instead, the values of the return of assets have a broad tail and indicate extremely positive values at higher probability than extreme negative ones (as mentioned earlier, it is because return values are limited by not being lower than -100).

In line with the above, Rudd-Clasing's (1982) opinion on the interpretation of risk can be regarded relevant.

"Risk is the uncertainty of investment outcomes. Technically the term risk is used to define all uncertainty about the mean outcome including both upside and downside possibilities. Thus, in contrast to the layperson, who would think of the downside outcome as risk and of the upside outcome as potential, a measure of total variability in both directions is typically used to summarize risk."

\subsection{Relativisation of the difference between risk and uncertainty}

In the neoclassical world of theories there was a sharp turn in the middle of the 2oth century related to the economic management of risk and uncertainty. At the beginning, it meant the difference between risk and uncertainty was questioned, later efforts were made to merge risk and uncertainty and to give one-sided preference to risk and to neglect uncertainty in the economic sense

Following an early interpretation by Savage (1954), Friedman (1976) provided a concise thesis why risk and uncertainty are undistinguishable as he wrote about consistent economic choice.

"In his seminal work, Frank Knight drew a sharp distinction between risk, as referring to events subject to a known or knowable probability distribution and uncertainty, as referring to events for which it was not possible to specify numerical probabilities. I have not referred to that distinction because I do not believe it is valid. I follow L.J. Savage's view of personal probability, which denies any valid distinction along these lines. We may treat people as if 
they assigned numerical probabilities to every conceivable event " (Friedman, 1976:282).

Interestingly, Friedman (1976) is looking for arguments to verify that risk and uncertainty are inseparable using Knigh's definitions. Knight always supposed that individuals had subjective faith with respect to uncertainty, and those expectations are of the same form as those in the context of risk. Accordingly, Knight wrote about a contradiction, as follows:

"The confusion arises from the fact that we do estimate the value of validity or dependability of our opinions and estimates, and such an estimate has the same form as a probability judgement; it is a ratio, expressed by a proper fraction." (Knight, 1921:23).

Knight makes it clear that individuals' subjective expectations are most important for him. Friedman's interpretations is difficult to understand, as Knight discussed the types of future events, their potential insurability and the part entrepreneurs played in shaping expectations at several points in his book, expressing that one cannot use mathematical probability or historical statistics to be the basis in most cases (particularly economic events).

Brooke (2010) emphasised Knight believed a successful entrepreneur had an ability to predict the future. He quoted Knight's relevant remark,

"Men differ in their capacity by perception and inference to form correct judgements as to the future course of events in the environment. This capacity, furthermore, is far from homogeneous, some persons excelling in foresight in one kind of problem situations, others in other kinds, in almost endless variety. (Knight, 1921:241).

Brooke also adds to confirm Knight's view that entrepreneurs do not only rely on their inherent abilities when making decisions, but luck also plays a part. Another important feature of an entrepreneur is their ability to endure uncertainty.

“....any degree of effective exercise of judgement or making a decision in a free society is coupled with a corresponding degree of uncertainty bearing or taking responsibility for those actions." (op.cit. p. 15).

Langlois-Cosgel (1993) presented an important argument with regard to the Knightian distinction between risk and uncertainty,

“...Because of the non-mechanical nature of economic life, novel possibilities are always emerging, and these cannot be easily categorized in an intersubjective way as repeatable instances" (Langlois-Cosgel, 1993:129).

There has been a long-standing debate on what forces in neoclassical economics, drove, in effect, the identification of uncertainty as risk. The general opinion is that mathematisation of economics played a major part, but the theory of 
economics underwent a re-definition of critical importance both with respect to the discipline and the methodology. Robbins' (1933) arguments served as the theoretical basis to the approach by Neumann-Morgenstern. Economics did not mean the buying and selling of goods, unemployment, and business cycles, but it touched upon specific aspects of human behaviour, i.e., choice among alternative options of using scarce resources. Boy (2009) called attention that NeumannMorgenstern (1944) were the first to present a consistent theory related to choice under uncertainty strongly opposing the idea that the human and psychological elements of economics should prevent a formalised treatment of human behaviour under uncertainty.

Hodgson (2011) has concluded that some representatives of neoclassical economics rejected the concept of uncertainty. A connection can be found in neoclassical economics between the decline of the concept of uncertainty after the middle of the century and the strong formalisation of economics, mainly because uncertainty is difficult to be built into the formalised models. Thus, the concept was simply banished from the neoclassical theory. Lucas wrote, "in cases of uncertainty an economic motive has no value” (Lucas, 1977:15). It recalls Arrow's analysis (1951) on Knight's uncertainty concept and the conclusion that lacking 'measurable probability' one cannot draft a theory of uncertainty. Both Arrow and Lucas argue that an 'economic justification' or theory must be quantitative. The ground for a major turn was that the decisive thinkers of neoclassical economics neglected, in the above context, Knight's and Keynes' objection that uncertainty cannot be quantified Instead, the concept of non-quantifiability was either rejected or uncertainty was given a subjective and quantifiable interpretation.

A major reason of the turn was presented by Friedman (1953) when he placed prediction to be the main goal of economists. He took the world as it is; he sought to construct an "engine" to analyse it, not a photographic reproduction of it" (1953:35). As a result,

"Truly important and significant hypotheses will be found to have "assumptions" that are wildly inaccurate descriptive representations of reality...A hypothesis is important if it "explains" much by little,...if it abstracts the common and crucial elements from the mass of complex and detailed circumstances... and permits valid predictions based on them alone. To be important, therefore, a hypothesis must be descriptively false in its assumptions ... Facts can never "prove" a hypothesis, they can only be used to reject it." (Friedman, 1953:14).

In a later work, Friedman (1976:282) moved from knowledge to the availability of knowledge; he characterised risk as covering not only the knowledge known but also the knowledge of probability to be learnt. An important criterion to differentiate risk from uncertainty is whether the quality of the cognitive situation 
of probabilities is of a sufficiently high quality, i.e., whether the knowledge of those probabilities is (sufficiently) authentic. Discussing uncertainty, Gardiner (2008:94) and Rawls (1999:134), to differentiate risk from uncertainty, do not examine if there are probabilities but ask instead if there are probabilities of high or low authenticity.. According to Roser (2017), many believe uncertainty can be transformed into risk.

Whatever the intention was by relativising the difference between risk and uncertainty, by preferring risk and neglecting uncertainty or by efforts to merge risk and uncertainty, the heart of the matter was that neoclassical economics confronted the concept of uncertainty, which happened because the predicting function had been placed first.

Le Roy-Singell have found that the distinction between risk and uncertainty in the mainstream economics had but a ceremonial role,

"economists, especially those working in the neoclassical tradition, invoke the distinction only in order to rule out uncertainty" (Le Roy-Singell, 1987:395).

The opinion of Boyle et al (2010) reflects an intention to close the gap between the views. Modelling individuals' choice under risk and uncertainty gets more complex if one knows more about how actually individuals make their choice under risk and uncertainty. Briefly, risk can be regarded as a subset of uncertainty, it is either quantifiable or measurable, while uncertainty indicates one does not know potential outcomes or the probability of their occurrence.

Faced with theoretical attempts to relativise the difference between risk and uncertainty, to merge the two categories or to neglect uncertainty, one should recall Knight's relevant thoughts. According to Brockhaus (1980), Knight divided uncertainty into a 'reducible' and an 'irreducible' component. Reducible uncertainty can be defined as (accidental) risk; while irreducible (accidental) uncertainty is the 'true' uncertainty. Risk can be analysed by the laws of mathematical probability, but true uncertainty is outside the realm of the numerical probability theory. The two categories are neither mutually exclusive nor independent of each other, neither can they be regarded as components separated or separable.

When risk and uncertainty are merged, an unfading thesis by Knight (1921:13) is ignored.

"Uncertainty must be taken in a sense radically distinct from the familiar notion of risk, from which it has never been properly separated... The essential fact is that "risk" means in some cases a quantity susceptible of measurement, while at other times it is something distinctly not of this character; and there are far-reaching and crucial differences in the bearings of the phenomena depending on which of the two is really present and operating...It will appear that a measurable uncertainty, or "risk" proper, as we shall use the term, is 
so far different from an unmeasurable one that is not in effect an uncertainty at all." Accordingly, the term "uncertainty" will be restricted to the cases of non-quantitative type.

Views presented lately reflect the general train of thought today:

"The present-day economic approach is increasingly giving up the distinction between risk and uncertainty and focuses on modelling the behaviour of business agents (producers and consumers) and market behaviour. Currently, uncertainty is a feature of the economic life and risk implies quantification for the purpose of measuring so that such tools can be used to mitigate its effects."(Motocu, 2009).

\subsection{Disintegration of the unity of risk taking and risk bearing: depersonalisation of risk taking}

When we discussed the origin of risk taking and risk bearing earlier, we said its first actor had been the owner-entrepreneur in the capitalist market economy, who had been both the owner of the capital risked and bearer of the consequences of risk. By the middle of the 2oth century ownership and operation of capital had moved apart, which resulted in a new situation in taking and bearing risk. Jensen-Meckling (1976) discussed the emerging excessive power of operators (managers) of capital in a high impact paper. The authors could foresee the risk of operators of capital making decisions for themselves and to the (short term) detriment of creditors and shareholders. Denning (2014), however, calls attention that Jensen-Meckling could not foresee the risk of violating the interests of shareholders, the threat of the combination in which operators of capital may conspire with shareholders who might have a vested interest in taking assets out of the company as short term profit to the detriment of customers, employees, the organisation, or the community the corporate entity is operating in damaging the whole society in the end.

Another argument is that operators of capital may manipulate stock prices by stock buybacks. This practice was not large-scale when the Jens-Meckling paper was published. According to Denning (2014), the authors could not imagine that, if barriers are lifted, the operators of capital may be committed to such wrongdoing obtaining thousands of billions of dollars in that way, which is, in fact, large scale manipulation of share prices. The representatives of the theory did not foresee, either the risk that the operators of capital could time the combination of different actions at wish so that their personal profit should be higher than that of common shareholders. 
The emergence of problems goes beyond the anomalies originating in the excessive power of managers (operators of capital). Institutional shareholders overlook what corporations do in that regard; they may even encourage them. Regulators are often unconcerned of systematic errors or irregularities under the pretext that the corporations involved are 'too large to fail'. Rating agencies accept profit originating in illegal actions. Analysts also welcome short-term profit, which means, objectively, the long-term erosion of corporate value.

Such fundamental changes in the corporate world and money markets have opened the way to a disproportionate concentration of capital. Denning (2014:14) cites a famous aphorism by Friedman,

"Concentrated power is not rendered harmless by the good intentions of those who create it."

Friedman was referring, of course, to government (state), to whose excesses he was exquisitely sensitive. On the other hand, such prophetic criticism was not levelled at excessive power (of any colouring) within the private sector. Mainly the overwrought and panicky escape to profit, it being placed above all has led to concentrated power in the hands of the few, which Friedman explicitly wanted to avoid. Concentration distorted competition processes by promoting the specific interest of channelling more and more of capital assets to the few.

The discipline of financial economics has arisen within economics beginning from the last one-third of the 2oth century. It has gained decisive importance in analysing investments, the relevant money markets, and risk. Financial economics assumes a world in which entrepreneurs are redundant and money markets have superior knowledge of customers' needs and the potential of resources. Ehret (2012) calls attention that models of financial economics systematically replace value-driven investments with speculation controlled by the theory. This newly formed discipline states that individual investors cannot beat the market. If markets are realistic, individual investors can only hope, in the best scenario, to reach the equilibrium price resulting from the competitive interference of buyers and sellers. More specifically, financial economics assumes that the conventional value driven investment approach is almost certainly erroneous. In the case of value driven investments investors estimate the present value of the future income from their investment. Since future income is uncertain, a conventional investor will use their experience, the available information networks, and their feelings to estimate the value of an investment. Assuming that the price of an investment item - for instance shares, bonds, listed goods - is moving towards equilibrium, a conventional investor will almost certainly be mistaken, since even their best estimation may differ from the equilibrium price. Based on the above, Taleb (2007) wrote that according to financial economics, the speculation strategies driven by the money markets surpass value driven investment strategies. 
The models of financial economics assume the normal distribution of asset prices. If their makers have confidence in a purely statistical approach, investors can construe investment portfolios that are the best match for their individual attitude of maximising return or avoiding risk (Fox, 2009; Markowitz, 1991).

Ehret (2012) underlines that financial economics offers investors an elegant range of models, which, in effect, renders the estimation of the future price of an asset possible by applying the data of the money markets only. Financial economics strives to transform conventional value driven investment exercises into acts driven by science with the help of economic theory and statistical calculation.

Speculators, who systematically assume equilibrium prices, separate prices from the opportunities and risks of production, which makes them insensitive to the consequences of infrequent events. Hypothetical equilibrium prices also distort the assessment of business performance. Financial economics transfers the role of entrepreneurs to an elegant scheme consisting of an economic theory, stochastic models and securities trading. Ehret (2012) emphasises financial economics distorts the exploration of business opportunities beyond the price inconsistencies of the money market. Its models cannot provide entrepreneurs with relevant models if they want to measure and control their business performance.

According to the tradition of neoclassical ideology, financial economics assumes that market players are in possession of sufficient knowledge to make rational decisions. Hayek (1945) challenged that view, stating that prices had meaning in an equilibrium, where buyers may indicate uncovered needs and producers may give effective signals about their unused resources. As long as prices are generated in any other way or for any other reasons, their potential to become meaningful instruments of economic communication is lost.

Entrepreneurs control their businesses as productive response to uncertainty and the lack of knowledge of individuals. While a rational market assumes complete knowledge and the application of stochastic methods to manage uncertainty, an entrepreneur strives to reveal uncertainty and direct their projects in a way to utilise the opportunities (Lackmann, 1977; Young, 1987). Ehret (2012) is right in saying that the application of financial economics separates entrepreneurs' judgement from asset valuation weakening in that way the accountability of entrepreneurs.

Fama's opinion (1980) is a good description of the essence of the forms of corporate ownership and governance emerging by the end of the 2oth century,

“...corporate governance is in the hands of managers who are more or less separated from the security holders. Since he holds the securities of many firms precisely to avoid having his wealth depend too much on any one firm, an individual security holder has no special interest in personally overseeing 
the detailed activities of any firm." Briefly, the negligence of risk bearing, preferred by security holders, creates the situation where security holders largely distance themselves from company control.

New developments have arisen in the management of risk and uncertainty in economic-financial decision making over the past three decades. The deregulation and liberalisation of the financial system emerging recently have incorporated a group of players of the financial markets that upset the fragile balance of shareholders. The players of this new group are termed financials in the literature of financial economics. They include top executives of companies, financial analysts, and consultants. This new group of professional or techno-bureaucratic actors trade on behalf of individual and institutional investors of discretionary funds and receive interest, dividends or investment as remuneration. The circumstances of managers' excess power and interest enforcement in companies unrestricted earlier have radically changed.

Following the deregulation and liberalisation of the financial system, the earlier two-player relationship (owner-operator of capital/manager) has become threeplayer as the so termed financials have become part of it. This 'third power' has overcome company managers and company managers started to act in the interest of techno-bureaucracy. All that has led to the accumulation of operational, financing, controlling and compensational risk. The increasing risk has become more difficult to be allocated, one can say, it has become ownerless. Risking 'others' resources in an explicitly non-prudent way has become an almost every day feature. Corporate governance could not prevent managers taking dangerous and damaging risks, which resulted in heavy losses.

Dizikes (2010) was right to point out that Knight's differentiation of risk and uncertainty could help analyse the behaviour of financial companies, investment institutions, the financials, and the whole of the capital market. Investment institutions and, in a wider sense, the players of the money markets viewed their accurate risk assessment with satisfaction both before and after the financial crisis (2008-2009) and thought with confidence they had been operating under the conditions of risk in Knight's sense, where they could assess the stakes of future outcomes. However, when such actors recognise their argumentation was false, they will understand they, in fact, are acting under the conditions of Knight's uncertainty and may be forced to curb trading. When investors recognise their assumptions of risk are no longer true, and the conditions of Knight's uncertainty prevail, the markets will witness "devastating efforts aimed at quality", when investors are trying to get rid of doubtful portfolios escaping into investments believed to be safe (Treasury bonds, precious metals).

Erroneous risk assessment, falsification of corporate performance, pursuit of exchange rate growth all cause imbalance of assessment and, as a result, risks taken 
to the expense of other economic actors will accumulate. Ever since ownership and operation of capital started to be separated, risk taking has become impersonal, uninstallable and unrestrictable. Expansive investments following managers' own utility optimum, meeting the profit expectation demands of analysts and consultants and many similar acts are typical examples of decisions made to the expense of other actors.

\section{CONCLUSIONS}

Emmett (2018) was clear-sighted to state that interest in great works remains in later times not because their message is timeless but because they convey ideas for the new generations of thinkers and economic actors that provide added value to their intellectual and entrepreneurial goals. We believe that both Knight's (1921) and Keynes's (1921) oeuvre have proved to be like that.

Knight's approach to risk-uncertainty and Keynes' management of uncertainty were new ideas of extreme importance in their age. They might have been lost for decades and were only re-discovered when current theories, lacking a relevant theory, could only explain little of unexpected events. Shackle was an exception $(1949 ; 1972)$. He was engaged in dealing with the critical interconnections of economics, time, expectations and uncertainty all his life. In the course of time, Shackle re-integrated expectations and uncertainty into the traditional Keynesian system, and using the logic of focus values, developed a mechanism that is consistent with the fragmented image provided by Keynes (1937).

Shackle (1972) believed the future of society should be regarded by people as something pre-defined, something the discovery of which can be, in fact, expected. He thought the future cannot be predicted; however, people can imagine the future and form subjective expectations about it. People act and are interactive based on those imaginations and expectations. Arthur (2013) emphasised the future would rise out of such (inter)activity; it can create surprises, both positive and (for a few people) negative. People respond and adapt to what the future presents when it becomes the present, again in the light of the uncertainty of an expected future. Arthur underlined it was an uninterrupted process, which can be characterised by both bottom-up and top-down causality without a known future or equilibrium. Individuals' actions and interactions jointly determine the future; the future emerging is one of the determinants of individuals' actions and interactions (Financial Risk, 2008).

The 2008-2009 financial crisis revealed the inability of financial institutions to make effective assessment of the risk of their investments. That was the reason why the crisis re-directed attention to earlier ideas about risk: Knightian uncer- 
tainty. Accordingly, one can talk about choice under uncertainty, when neither decision outcomes nor the probability of their occurrence is known. It can be decision makers' uncertainty, which means they do not know, thus, cannot comprehend the options, cannot avoid outcomes that are adverse for them and cannot make good decisions - in the end, they cannot improve their situation. The failure of actual choices may increase decision makers' uncertainty. It is absolutely subjective and depends on individuals' state of mind. It can also happen one cannot choose between two certain events although both their outcomes and probabilities are known. According to Knight, objective assessment is impossible under uncertainty.

Rewording Knigh's risk-uncertainty somewhat, Dizikes (2010) says risk can be applied to situations where the outcome of a situation is unknown, but the stakes placed by risk takers can be measured accurately. On the other hand, uncertainty can be applied in situations where all the information needed to identify the stakes accurately is unknown. Knight said there was fundamental difference between the reward to be received for taking known risks and assuming risks the value of which is unknown. Known risk is easy to be converted into effective certainty, while true uncertainty, as Knight termed it, is not prone for measurement. Knight (1921:43) in the section cited made a special detour to discuss the relationship of risk and insurance when he wrote the following:

"It is admitted that the entrepreneur may get rid of risk in some cases for a fixed cost, by means of insurance. But by the act of insurance the businessman abdicates so much of his entrepreneurship, for it is manifest that an entrepreneur who should eliminate all his risks by means of insurance would have left no income at all which was not resolvable into wages of management and monopoly gains. To the extent to which the businessman insures, he restricts the exercise of his peculiar function, but the risk is merely transferred to the insurer, who by accepting it becomes himself an entrepreneur and the recipient of an un-predetermined residue or profit. The reward of an insurer is not the premium he receives, but the difference between that premium and the loss he eventually suffers."

Knight held the view that economic events are so complex that predictions are always struggles with "true" uncertainty but not with risk. Past data used to predict risk may not reflect current conditions. According to Knight, "risk" should be applied to highly controlled environments, such as the purer varieties of gambling, while "uncertainty" can be used for almost any other case. The distinction, in effect, relates to measurability. Decision makers cannot avoid taking risks whether voluntary or enforced; they can be regular or sudden threats, explicit or latent risks, or controllable versus uncontrollable risks. Whichever version is there, uncertainty surrounding economic decisions cannot be eliminated. 
As uncertainty was banished from the neoclassical world of theories, more and more complex financial products and more and more sophisticated risk-related instruments have been appearing on the markets for the past decades while fewer and fewer investments have been categorised as uncertain. As Emmett (2018) indicated, two important events occurred. One was the 2008-2009 financial crisis caused mostly by the instruments aimed to be managing financial risk which were said to be risk mitigating. The other event was Taleb's (2007) publication, which used the analogy of a "black swan" to revive Knight's concept of uncertainty, since the symbol marked a "highly unlikely event". Taleb denied that uncertainty could be managed by risk markets. Instead, he worded some Knightian arguments. According to Taleb, since one cannot be fully protected from uncertainty, one must build a robust enterprise, a robust theory of economics, robust social institutions to resist uncertainty and avoid harmful outcomes. According to Emett (2018), such actions may require costs, they may place restrictions on other aspects of corporate operations and open new roads to new opportunities.

Keynes' (1921) theory of logical probability is in an intermediate position between the subjective and objective theory of probability. At the end of his Treatise, he adds a rhyme on probability expressing his special opinion. ${ }^{20}$ Keynes here says probability is a double-edged thing with a double meaning. In Sakai's interpretation (2015:4), it can be false and dangerous on the one hand that may become the adversary of truth. On the other hand, it can lead to truth in the sense it plays the part of the weak side in the process of seeking truth. In that sense, the concept of probability can be both dreary or fruitful. In fact, nobody can predict which version is applicable.

Both Knight (1921) and Keynes (1921) applied the term uncertainty to events having no calculable probability. Knight viewed risk as quantity "disposed to be measured" while uncertainty was regarded as "non-measurable" and "notquantitative" (1921:19-20). According to Keynes, uncertainty applies to situations where "opinions as to their prospective yield are.. subject to fluctuations, precisely for the reason already given, namely, the flimsiness of the basis of knowledge on which they depend" (Keynes, 1937:217).

Knight and Keynes, two great thinkers of economics, introduced non-measurable uncertainty into the theory and analysis of economics as a novelty and provided in-depth analysis of how it differs from measurable risk. One must be aware

20 "False and treacherous Probability, Enemy of truth, and friend to wickedness; With whose bleare eyes Opinion learnes to see, Truth's feedble party here, and barrennesse." (Keynes, 1921:466). 
that the two terms intentionally separated risk and uncertainty from each other. Knight wrote the following,

“...Uncertainty must be taken in a sense radically distinct from the familiar notion of Risk, from which it has never been properly separated. The term "risk", as loosely used in everyday speech and in economic discussion, really covers two things, which, functionally at least, in their causal relations to phenomena of economic organization, are categorically different." (Knight, 1921:19).

Sakai (2015) also emphasises that Knight radically differentiated uncertainty from risk, since risk and uncertainty must be different categories. Knight himself used strong terms, such as "radically unlike" and "categorically different": The question may arise, why the two things are different? Knight remarks the following in that context,

“...A measurable uncertainty, or "risk" proper, as we shall use the term, is so far different from an unmeasurable one that it is not in effect an uncertainty at all. We shall accordingly restrict the term "uncertainty" to cases of the non-quantitative type. It is this "true" uncertainty, and not risk, as has been argued, which forms the basis of a valid theory of profit and accounts for the divergence between actual and theoretical competition." (Knight, 1921:20) ${ }^{21}$

Bernstein (1996:215) believes uncertainty as a "radically separate concept" could not suffice to be the dominant pattern of decisions of choice at a time (the second half of the 2oth century) when thinkers were striving to transform economics into a science by studying how it behaves when individuals are absolutely rational and act on purely economic considerations.

In the case of Keynes' animal spirits, the emphasis on "the features of human nature" is the argument verifying that "the majority of our positive actions rather depend on spontaneous optimism than mathematical expectations' (Keynes, 1936:161). According to Skidelsky (2009:135), Keynesian uncertainty is linked to positive and negative beliefs about the future. Neither of them can be properly explained as they are exposed to unexpected changes. Skidelsky interpreted Keynes' idea so that if we do not have a way to learn the future, it is rational and justified to act in accordance with expectations, which may originate in conventions, principles, traditions, or habits.

21 VON Mises $(1928$; 1957) formulates the importance of uncertainty in Keynes' system even more clearly, when he writes Keynes demonstrated for all that uncertainty had been the real driving force of economic action. In a world with no uncertainty where everything is a priori defined (and predictable), individuals' role is restricted to being mere executors of logical and necessary actions. 


\section{REFERENCES}

Akerlof, G. A. - Shiller, R. J. (2009): Animal Spirits: How Human Psychology Drives the Economy and Why it Matters for Global Capitalism. Princeton, N. J.: Princeton University Press.

Andreoni, J. - Sprenger, C. (2012): Risk Preferences are t Time Preferences. American Economic Review, 102(7), 3357-3376.

Arrow, K. (1971): Essay in the Theory of Risk Bearing. Markham Publishing Company.

Arrow, K. (1971): Insurance, Risk and Resource Allocation. University of Illinois at Urbana.

Arrow, K. (1951): Alternative Approaches to the Theory of Choice in Risk-Taking Situations. Econometrica, 19, 404-437.

Azariadis, C. (1981): Self-fulfilling Prophecies. Journal of Economic Theory, 25, 380-396.

Balgah, R. A. - Buchenrieder, G. (2012): Risk, Uncertainty and Decision Making. An Empirical Test of Irving Fisher's Theory of Interest. Bamenda: Catholic University of Cameroon, 1(2), 33-41.

BeRnoulli, D. $(1738 ; 1955)$ : Exposition of a new theory on the measurement of risk. Reprinted in 1955 in Econometrica 22(1), 23-36.

Bernstein, P. L. (1995): Risk as a History of Ideas. Financial Analyst Journal, 51(1), 7-11.

Bernstein, P. L. (1996): Against the gods: the remarkable story of risk. New York: Wiley.

Bogle, P. - Garlappi, L. - Uppal, R. - Wang, T. (2010): Keynes Meets Markowitz: The Trade of Between Familiarity and Diversification. AFA Atlanta Meetings Paper, 41.

Boy, N. (2008): Calculating Risk and Uncertainty. King's College Risk Research Symposium, 10.

Brockhaus, R. H. (1980): Risk Taking Propensity of Entrepreneurs. Academy of Management Journal, 29(1), 509-520.

Brooke, G. T. F. (2010): Uncertainty, Profit and Entrepreneurial Action: Frank Knight's Contribution Reconsidered. Department of Economics, University of Auckland. New Zeland, 25.

Butos, W. N. - Koppl, R. G. (1995): The Varieties of Subjectivism: Keynes and Hayek on Expectations. History of Political Economy, 29(2), 1-61.

Carabelli, A. (1988): On Keynes's Method. London: Mac Millan

Chapman, K. (2019): The Concept of Risk in Economics. Free Essay Samples Database, 19.

Davidson, P. (1991): Is Probability Theory Relevant for Uncertainty. A Post Keynesian Perspective. Post Keynesian Economics, 5(1), 129-143.

Denning, S. (2014): The Unanticipated Risk of Maximizing Shareholder Value. Forbes, 14 Octobre.

Dequech, D. (1999): Expectations and confidence under uncertainty. Journal of Post Keynesian Economics, 75(1), 643-669.

DequeCH, D. (2000): Fundamental uncertainty and ambiquity. Eastern Economic Journal, 26, 41-60.

Dequech, D. (2005): Confidence and Alternative Keynesian Methods of Asset Choice. Review of Political Economy, 17(4), 533-547.

Dizikes, P. (2010): Explained: Knightian uncertainty. MIT News, June 2

Dow, A. - Dow, S. C. (2011): Animal Spirits Revisited. Manuscript 1087, Berkley Electronic Press, 23.

EHRET, M. (2012): Financial socialism - the role of financial economics in economic disorganization. Nottingham: Business School 34 .

Емmetт, R. (2018): A Century of Risk, Uncertainty and Profit. Econlib Featured Article, Dec. 3.

Epper, T. - Fehr-Duda, H. (2018): The Missing Link: Unifying Risk Taking and Time Discounting. Working Paper 96, University of Zürich. 
Epstein, L. G. - ZIN, S. E. (1989): Substitution, Risk Aversion and Asset Returns: A Theoretical Framework. Econometrica, 7(4), 937-969.

Fama, E. F. (1980): Agency problems and the theory of the firm. Journal of Political Economy, 88(2), 288-307.

Fisher, I. S. (1919): The Nature of Capital and Income. New York: Macmillan.

FISHeR, I. S. (1930): The Theory of Interest. As Determined by Impatience to Spend Income and Opportunity to Invest It. New York: Macmillan.

Fontana, M. - Marchionatti, R. (2007): Endogenous Animal Spirits and Investment. An Agentbased Model. Working Paper Series, Università di Torino.

Friedman, M. - Savage, L. (1948): The Utility Analysis of Choices Involving Risk. Journal of Political Economy, 56(4), 279-304.

Friedman, M. (1953): The Methodology of Positive Economics. In: Friedman, M.: Essays in Positive Economics. Chicago: University of Chicago Press, 3-43.

Fuller, J. - Jensen, M. C. (2002): Just Say to Wall Street: Putting a Stop to the Earnings Game. Journal of Applied Corporate Finance, 4, 41-46.

Gerrard, B. (1994): Animal Spirits. In: Arestis, P. - Sawyer, M. (eds): The Elgar Companion to Radical Political Economy. Cheltenham: Edward Elgar.

Gneezy, U. - List, J. A. - Wu, G. (2006): The Uncertainty Effect: When A Risky Prospect is Valued Less Than Its Worst. Possible Outcome. Quarterly Journal of Economics, 121(4), 1283-1309.

Hamouda, O. F. - Smithin, J. N. (1988): Some Remarks on "Uncertainty and Economic Analysis". The Economic Journal, 98, 159-164.

Harvey, J. (2008): Financial Risk Management. Topic Gateway Series, 47.

Havas, Á. (1993): Kockázatelemzés - mágia vagy tudomány? [Risk analysis - magic or science?]. Iskolakultúra, 3(23), 21-28.

Hayek, F. A. (1945): The Use of Knowledge in Society. American Economic Review, 35(5), 19-30.

Haynes, J. (1895): Risk as an economic factor. The Quarterly Journal of Economics, 9(4), 409-449.

Hicks, J. R. (1931): The Theory of Uncertainty and Profit. Economica, 32(2), 170-189.

Hirshleifer, J. - Riley, J. G. (1979): The Analytics of Uncertainty and Information - An Expository Survey. Journal of Economic Literature, 17, 1422-1441.

Hodgson, G. M. (2011): The Eclipse of Uncertainty Concept in Mainstream Economics. Journal of Economic Issues, 45(1), 159-176.

Hume, D. (1739): A Treatise on Human Nature. Edinburgh.

Jensen, M. C. (2005): Agency Costs of Overvalued Equity. Financial Management 1, 519.

Jeronimo, H. M. (2014): Risicophrenia and "animal spirits": clarifying the notions of risk and uncertainty in environmental problems. Scientiae Studia, 12, No spec. Sao Paulo.

Jevons, W. S. (1871): The Theory of Political Economy. London, New York: Macmillan

Kahneman, D. (1979): Prospect Theory: An Analysis of Decision Under Risk. Econometrica, 47(2), 263-291.

Keynes, J. M. (1910): Six lectures to London School of Economics. In: Indian Currency and Finance.

Keynes, J. M. (1921): The treatise on probability. London: Mac Millan

Keynes, J. M. (1925; 1979): A Treatise on money. Part 2. The Applied Theory of Money.

Keynes, J. M. (1937): The General Theory of Employment. Quarterly Journal of Economics, 51, 209223.

Keynes, J. M. (1937; 1979): Some economic consequences of a declining population. Eugenics Review, 29(1). 
Keynes, J. M. (1979): Collected Works. Cambridge University Press.

Keynes, J. M. (1983): Collected Writings. Investment and Editorial Economic Articles and Correspondence. New York: Mac Millan.

KIRKPATRICK, G. (2009): Corporate Governance: Lessons from the Crisis. OECD Journal: Financial Market Trends, June 61-87.

Kirzner, I. M. (1973): Competition and Entrepreneurship. Chicago, London: University of Chicago Press.

Kirzner, I. M. (1997): Entrepreneurial Discovery and the Competitive. Market Press: An Austrian Approach. Journal of Economic Literature, 35(3), 60-85.

KNight, F. H. (1921): Risk, Uncertainty and Profit. Boston: Houghton Miffin Company.

Koppl, R. - Moggridge, D. - Ozava, T. (1992): Correspondance. Journal of Economic Perspectives, 6(3), 207-212.

Koppl, R. (1991): Retrospectives Animal Spirits. Journal of Economic Perspectives, 5, 203-210.

KovÁcs, K. (2020): Relative consumtion with multiple reference points under uncertainty. Economics and Sociology, 13(4), 61-80.

Kregel, J. A. (1976): Economic Methodology in the Face of Uncertainty: The Modelling Methods of Keynes and the Post-Keynesians. Economic Journal, 86(2), 209-225.

Langlois, R. N. - Cosgel, M. M. (1993): Frank Knight on Risk Uncertainty and the Firm: a New Interpretation. Economic Inquiry, 31, 456-465.

Lawson, T. (1985): Uncertainty and Economic Analysis. Economic Journal, 95, 909-927.

Lawson, T. (1988): Probability and Uncertainty in Economic Analysis. Journal of Post-Keynesian Economics, 11(1), 38-65.

Le Roy, S. F. - Singell, D. (1987): Knight on Risk and Uncertainty. Journal of Political Economy, 95, 394-406.

Loewenstein, G. - Thaler, R. H. (1989): Intertemporal Choice. Journal of Economic Perspectives, 3(4), 181-193.

Loomes, G. - Sugden, R. (1986): Disappointment and Dynamic Consistency in Choice Under Uncertainty. Review of Economic Studies, 53(2), 271-282.

Lucas, R. (1977): Understanding business cycles. Carnegie Rochester Conference Series Public Policy, Elsevir 5(1), 7-29.

Lucas, R. (1980): Methods and Problems in Business Cycle Theory. Journal of Money, Credit and Banking, 12(4), 696-715.

Marchionatti, R. (1999): On Keynes Animal Spirits. Kyklos, 52(3), 415-439.

Markowitz, H. (1952): Portfolio Selection. Journal of Finance, 7, 77-91.

Markowitz, H. (1952): The Utility of Wealth. Journal of Political Economy, 60, 151-158.

Markowitz, H. M. (1959): Portfolio Selection: Efficient Diversification of Investments. New York: John Wiley and Sons

Markowitz, H. M. (1991): Foundations of Portfolio Theory. Journal of Finance, 46(6), 469-477.

Meltzer, A. H. (1982): Rational Expectations, Risk, Uncertainty and Market Responses. In WACHTEL, P. (ed.): Crises in the Economic and Financial Structure. Washington DC: Lexington Books.

Mill, J. S. (1885): Principles of Political Economy with of their applications to social philosophy. New York: Oxford University Press.

Mises, R. v. (1928/1957): Probability, Statistics and Truth. English Edition. London: George Allen and Unwin.

Moggridge, D. (1992): The Source of Animal Spirits. Journal of Economic Perspectives, 6(3), $207-209$. 
Moscati, I. (2016): Retrospectives: How Economist Came to Accept Expected Utility Theory: The Case of Samuelson and Savage. Journal of Economic Perspectives, 30(2), 219-236.

Moтocu, M. (2009): Managementul riscului în economie. Cluj-Napoca: Risoprint, 14.

Neumann, J. - Morgenstern, O. (1944): Theory of Games and Economic Behavior. Princeton University Press.

Neumann, J. (1937; 1965): A Model of General Economic Equilibrium. Review of Economic Studies, $13,1-9$.

Neumann, J. (1928): Zur Theoriie der Gesellschaftsspiele. Matematische Annalen, 100, 295-320.

O’ Donnell, R. (1990): An overview of probability, expectations, uncertainty and rationality in Keynes's conceptual framework. Review of Political Economy, 2(3), 253-266.

O’ Donoghue, T. - Rabin, M. (1999): Doing It w or Later. American Economic Review, 89(1), 103-124.

Oxford English Dictionary (2008): Online edition: Risk and Uncertainty szócikk. Oxford University Press.

PArk, K. F. - Shapira, Z. (2017): Risk and Uncertainty. The Palgrave Encyclopedia of Strategic Management. 250-251.

Pigou, A. C. (1920): The Economics of Welfare. London: Macmillan.

Rabin, M. - Thaler, R. H. (2001): Anomalies: Risk Aversion. Journal of Economic Perspectives, 15(1), 219-232.

Ricardo, D. (1821): On the Principles of Political Economy and Taxation ( $3^{\text {rd }}$ edition). London: Murray.

Roggi, O. - Ottanelli, O. (2013): An Evolutionary Perspective on the concept of risk, uncertainty and risk management. In Roggi, O. - Altman, E. (eds.): Managing and Measuring Risk. World Scientific Series in Finance, 5.

Roser, D. (2017): The Irrelevance of the Risk - Uncertainty Distinction. Science Engeneeiring Ethics $23,1487-1407$.

Rudd, A. - Clasing, H. K. (1982): Modern Portfolio Theory: the Principles of Investment Management. Homewood Illinois Dow Jones Irvin.

Runde, J. (1990): Keynesian Uncertainty and the Weight of Arguments. Economics and Philosophy 6(2), 275-292.

Runde, J. (1998): Clarifying Frank Knight's Discussion of the Meaning of Risk and Uncertainty. Cambridge Journal of Economics, 22(5), 539-546.

SAKAI, Y. (2015): J. M. Keynes versus F. H. Knight. How to deal with Risk, Probability and Uncertainty. Kyoto: Minerva Publishing Co.

SAKAI, Y. (2018): On the Economics of Risk and Uncertainty. Shiga University, Discussion Paper Series, A-28, 26.

Samuelson, P. A. (1937): A Note of Measurement of Utility. Review of Economic Studies, 4, 155-161.

Samuelson, P. A. (1947): Foundations of Economic Analysis. Harvard University Press.

Samuelson, P. A. (1963): Risk and Uncertainty: A Fallacy of Large Numbers. Scientia, 98, 108-113.

SAvage, L. (1954): The Foundation of Statistics. New York: Dover.

SCHILIRÒ, D. (2017): Economics versus psychology. Risk, uncertainty and the expected utility theory. MPRA Paper 83366, June 10. Department of Economics, University of Messina.

ShACKLE, G. L. S. (1949): Expectation in Economics. Cambridge University Press

Shackle, G. L. S. (1967):The Years of High Theory: Invention and Tradition in Economic Thought 1926-1939. Cambridge University Press. 
Shackle, G. L. S. (1972): Epistemics and Economics: A Critique of Economic Doctrines. Cambridge: Cambridge University Press.

Shane, F. - Loewenstein, G. - O’Donoghue, T. (2002): Time Discounting and Time Preferences: A Critical Review. Journal of Economic Literature, 40(2), 351-401.

Simon, H. A. (1955): A Behavioral Model of Rational Choices. Quarterly Journal of Economics, 69, 99-118.

Slutsky, E. (1915): On the Theory of the Budget of the Consumer. In: Stigler, G. J. - Bouldings, K. E. (ed., 1952): Reading in Price Theory. Illinois, Homewood, 2. chapter.

Sмiтн, A. (1956; 1776): An Inquiry into the Nature and Causes of Wealth of Nations. Chicago: P. F. Collier and Sons.

Starmer, C. (200o): Developments in n-Expected Utility Theory: The Hunt for a Descriptive Theory of Choice Under Risk. Journal of Economic Literature, 38, 332-382.

TAleb, N. (2007): The Black Swan: The Impact of the Highly Improbable. Random House.

Thaler, R. H. (1980): Toward a Positive Theory of Consumer Choice. Journal of Economic Behavior and Organization, 1(1), 39-6o.

Thaler, R. H. (1985): Mental Accounting and Consumer Choice. Marketing Science, 4(3), 199-214.

Toma, S. V. - Chitita, M. - SARPe, D. (2012): Risk and Uncertainty. Procedia Economics and Finance, 3, 975-980.

Townshend, H. (1937): Liquidity premium and the theory of value. Economic Journal, 47, 157-169.

Tversky, A. - Kahneman, D. (1981): The Framing on Decisions and the Psychology of Choice. Science, 211(4481), 453-458.

Tversky, A. - Kahneman, D. (1992): Advances in Prospect Theory: Cumulative Representation of Uncertainty. Journal of Risk and Uncertainty, 5(4), 297-323.

Vough, K. I. (1980): Economic Calculation Under Socialism: the Austrian Contribution. Economic Inquiry, 18(10), 535 .

WeIL, P. (1989): Increasing returns and animal spirits. American Economic Review, 79, 889-894.

Weintraub, E. R. (1975): Uncertainty and the Keynesian Revolution. History of Political Economy, 7, 530-548.

Willet, A. (1901): The Economic Theory of Risk and Insurance. University Press of Pacific. 